A general solution of the problem of mixing of subpopulations, and its application to risk- and age- structured epidemic models

for the spread of AIDS

by

\title{
Stavros Busenberg
}

and

Carlos Castillo-Chavez

BU-1063-MB

December 1990 


\title{
A general solution of the problem of mixing of subpopulations, and \\ its application to risk- and age- structured epidemic models
}

for the spread of AIDS

\author{
Stavros Busenberg \\ Department of Mathematics \\ Harvey Mudd College \\ Claremont, California 91711
}

U.S. A.

\author{
Carlos Castillo-Chavez \\ Biometrics Unit, Center for Applied Math., \\ Population and Development Program \\ 341 Warren Hall \\ Cornell University \\ Ithaca, NY 14853-7801 \\ U. S. A.
}

\begin{abstract}
A central aspect in the study of the dynamics of sexually-transmitted diseases is that of mixing. The study of the effects of social structure in disease dynamics has received considerable attention over the last few years as a result of the AIDS epidemic. In this paper we formulate a generalization of the Blythe and Castillo-Chavez social/sexual framework for human interactions through the incorporation of age-structure, and derive an explicit expression in terms of a preference function for the general solution to this formulation. We emphasize the role played by proportionate mixing, the only separable solution to this mixing framework, through the discussion of several specific cases, and we formulate an age-structured epidemic model for a single, sexually-active homosexual population, stratified by risk and age, with arbitrary risk and age-dependent mixing as well as variable infectivity. In the special case of proportionate mixing in age and risk, an explicit expression for the basic reproductive number is computed.
\end{abstract}

\section{Introduction}

Recent estimates put the number of HIV-infected (i.e., infected with the human immunodeficiency virus, the etiological agent for AIDS) at between 800,000 and 1,200,000 individuals 
in the United States. The World Health Organization estimates the number of HIV carriers worldwide at $5,000,000$ to $10,000,000$. The Center for Disease Control in Atlanta (U.S) reports, as of December of 1989 , more than 112,000 cases of "full-blown" AIDS, of which over 70,000 individuals have died. Estimated costs for the treatment of and caring for individuals with AIDS run into the billions of dollars. This grim scenario has motivated researchers to develop mathematical models to identify and/or improve our understanding of the mechanisms responsible for HIV transmission and for the evaluation of the relative merits of possible control measures. Recent reviews of the literature on models include those of Anderson (1988,1989), Castillo-Chavez (1989a, b), and Schwager et al. (1989), while an extensive study of some of the most recent work on the use of mathematical and statistical modeling of the dynamics of HIV at the individual (immune system) or population level can be found in the recent collection of articles published by Springer-Verlag (see Castillo-Chavez 1989b).

Some of the questions that can be approached through the use of mathematical models (see Hethcote and Yorke 1984, Anderson 1988, May and Anderson 1989, Castillo-Chavez et al. 1988, 1989a, Castillo-Chavez et al. 1989b, c, Diekmann et al. 1989) include: the possibility of invasion (i.e., whether or not a disease can colonize successfully a given population of susceptibles at steady state), the determination of thresholds, the possibility that a disease may reach an endemic state, and whether or not a disease can regulate a population. The preliminary work of several AIDS modeling research groups (see Anderson 1988, Castillo-Chavez 1989b) has already made numerous contributions. Researchers have demonstrated that the infectious period distribution with its large mean and variance implies that a rise in seropositivity will precede the rise in AIDS, possibly by years. Furthermore, heterogeneity in infectivity and the possibility of two infectivity peaks (see Francis et al. 1984, Lange et al. 1986, Salahuddin et al. 1984) will have a major effect on the shape of the epidemic curve (see Hyman and Stanley 1989, Thieme and Castillo-Chavez 1989a, b). Selection due to AIDS-induced mortality will decrease the population's mean sexual activity, i.e. the average rate of sexual partner change, and hence make the evaluation of the effectiveness of education programs difficult (see Castillo-Chavez et al. 1989e, Anderson et al. 1989). The magnitude of the basic reproductive number, or the number of secondary infections generated by a "typical" infectious 
individual in a population of susceptibles, in combination with the shape of the incubation period distribution, will have a major effect on the first episode and potentially on the long term dynamics of HIV as well. Predictions are not possible without an increased understanding of social dynamics (see Hyman and Stanley 1989, Jacquez et al. 1988, Gupta et al. 1989, Castillo-Chavez et al. 1989d, e, Huang et al. 1989, Cooke et al. 1989, Dietz 1988, Dietz and Hadeler (1988), Hadeler 1989a, b, May and Anderson 1989, Blythe and Castillo-Chavez 1989, Castillo-Chavez and Blythe 1989, Anderson et al. 1989, Gupta et al. 1989). These researchers have shown that epidemic models can be very sensitive to changes in the sexual/social mixing structures, and that not all of them exhibit the same global dynamics.

Much of this recent work has highlighted the need to study systematically the effects of mixing in disease dynamics. An in-depth study of the effects of mixing requires a suitable axiomatic framework incorporating the natural constraints involved in mixing. Recently Blythe and CastilloChavez (1989) and Castillo-Chavez and Blythe (1989)--hereafter both articles will be referred to as BCC--formulated such a framework for continuously distributed characteristics and found a large class of new solutions to the mixing constraints. Their family of solutions is based on the use of a preference or acceptance function allowing for the incorporation of preference in the mixing process. This family of solutions includes Nold's preferred mixing (see Nold 1980, Hethcote and Yorke 1984), proportionate mixing, and like-with-like mixing (see Busenberg and Castillo-Chavez 1989). Furthermore, BCC have used this family of solutions to illustrate the combined effects on the shape of the mixing function of the interactions among individuals belonging to groups with specified preferences and levels of risk and the mixing constraints imposed naturally upon this population of interacting groups through their own distribution of sexual activity. These numerical simulations corroborated and extended the numerical results of Hyman and Stanley (1988, 1989). In addition, special representatives of these mixing functions have been incorporated into dynamic models for the sexual spread of HIV. The mathematical analyses and numerical simulations of these models have shown the dramatic effects on disease dynamics of the choice of a mixing function (see Hyman and Stanley 1989, Anderson et al. 1989, Jacquez et al. 1988, Castillo-Chavez et al. 1989d, e, Huang 1989, 
Cooke et al. 1989, Gupta et al. 1989, and Huang et al. 1990).

The main objectives of this paper include generalizing the mixing framework (BCC) and deriving of an explicit expression for the general solution to the mixing problem for a population stratified by age and level of sexual activity, formulating an age-structured epidemic model for a single homosexually active population with arbitrary social/sexual age-dependent mixing, and computing the reproductive number for a proportionately (in age and risk) mixing population.

This paper is organized as follows: Section 2 axiomatically characterizes the mixing function and describes its role in disease dynamics by deriving an expression for the incidence (which determines the number of new cases per unit time). Section 3 discusses several mixing functions that arise from different constitutive relationships. Section 4 derives an explicit expression for the general solution of the mixing problem in terms of a preference function. Section 5 formulates a general dynamic model for the spread of HIV/AIDS for a homosexually-active age- and risk-structured population and computes its basic reproductive number in the case of proportionate mixing. Section 6 discusses the relevance of the results presented in this article, briefly outlines our results on two-sex mixing frameworks, and suggests future directions of research.

\section{Mixing framework}

The formulation described in this section can be used in the modeling of social or sexual mixing interactions. For example, while the mixing function can describe the proportion of "dates" between individuals in distinct groups, or it can represent the proportion of sexual partnerships or sexual contacts between these individuals, other interpretations are possible. In addition, the mixing function can be generalized to include the geographical distribution or the geographical movement of individuals through the use of "localized" mixing functions, i.e., functions that represent the proportion of partnerships formed between individuals from clearly defined groups (socially, demographically, etc.) at a particular geographical location. The local geographical heterogeneities can then be linked through the specification of migration or movement matrices (see Sattenspiel 1987a, b, 
Sattenspiel and Simon 1988). Therefore, our approach allows for the specification of a spatial mixing framework. In this paper, however, we concentrate on the study of localized mixing functions. We begin by considering the interactions of a single, socially-homogeneous group of individuals who are structured according to the following variables: $a=$ age; $\tau=$ time (or age) since infection; $r=$ activity or risk level. We let $\mathrm{N}(\mathrm{r}, \mathrm{a}, \tau, \mathrm{t})$ denote the total population density per unit age, activity, and time since infection, at time t. This population is divided into the following epidemiological classes: $\mathrm{S}$ = susceptible; $\mathrm{I}=$ asymptomatic or slightly symptomatic infective; $\mathrm{A}=$ highly symptomatic infective. This classification is fairly general and includes implicitly the traditional infected, but not infective class E (see Busenberg and Castillo-Chavez 1989). We assume that $\tau$ is a hidden internal variable that does not distinguish individuals other than through their level of infectivity, and perhaps mortality. When modeling the sexual transmission of AIDS, we assume that A-individuals (i.e. individuals with severe symptoms or "full-blown" AIDS) are sexually inactive and hence that

$$
\mathrm{T}(\mathrm{r}, \mathrm{a}, \mathrm{t})=\mathrm{S}(\mathrm{r}, \mathrm{a}, \mathrm{t})+\int_{0}^{\infty} \mathrm{I}(\mathrm{r}, \mathrm{a}, \tau, \mathrm{t}) \mathrm{d} \tau
$$

represents the total age and activity-level density of a population active in disease transmission contacts. Sexual mixing is defined through the mixing function $\rho$. Specifically,

$$
\begin{aligned}
\rho\left(\mathrm{r}, \mathrm{a}, \mathbf{r}^{\prime}, \mathrm{a}^{\prime}\right)= & \text { the proportion of partners of an }(\mathbf{r}, \mathbf{a}) \text { individual } \\
& \text { (i.e., a person of activity level } \mathbf{r} \text { at age } \mathbf{a}), \text { with }\left(\mathbf{r}^{\prime}, \mathbf{a}^{\prime}\right) \\
& \text { individuals. }
\end{aligned}
$$

$C(r, a, W(T(., ., t)))=$ the expected or average number of partners per unit time of an $(r, a)$ individual given that the effective population size is $W(T(., ., t))$ at time $t$. We assume $C \geq 0$.

The following natural conditions characterize the mixing function:

(i) $\rho \geq 0$,

(ii) $\int_{0}^{\infty} \int_{0}^{\infty} \rho\left(r, a, r^{\prime}, a^{\prime}, t\right) \mathrm{dr}^{\prime} \mathrm{da}^{\prime}=1$, if $\mathrm{C}(\mathrm{r}, \mathrm{a}, \mathrm{W}(\mathrm{T}(\cdot, \cdot, \mathrm{t}))) \mathrm{T}(\mathrm{r}, \mathrm{a}, \mathrm{t}) \neq 0$,

(iii) $\rho\left(\mathrm{r}, \mathrm{a}, \mathrm{r}^{\prime}, \mathrm{a}^{\prime}, \mathrm{t}\right) \mathrm{C}(\mathrm{r}, \mathrm{a}, \mathrm{W}(\mathrm{T}(., ., \mathrm{t}))) \mathrm{T}(\mathrm{r}, \mathrm{a}, \mathrm{t})=\rho\left(\mathrm{r}^{\prime}, \mathrm{a}^{\prime}, \mathrm{r}, \mathrm{a}, \mathrm{t}\right) \mathrm{C}\left(\mathrm{r}^{\prime}, \mathrm{a}^{\prime}, \mathrm{W}(\mathrm{T}(., ., \mathrm{t}))\right) \mathrm{T}\left(\mathrm{r}^{\prime}, \mathrm{a}^{\prime}, \mathrm{t}\right)$,

(iv) $\mathrm{C}(\mathrm{r}, \mathrm{a}, \mathrm{W}(\mathrm{T}(., ., \mathrm{t}))) \mathrm{T}(\mathrm{r}, \mathrm{a}, \mathrm{t}) \mathrm{C}\left(\mathrm{r}^{\prime}, \mathrm{a}^{\prime}, \mathrm{W}(\mathrm{T}(., ., \mathrm{t}))\right) \mathrm{T}\left(\mathrm{r}^{\prime}, \mathrm{a}^{\prime}, \mathrm{t}\right)=0 \Rightarrow \rho\left(\mathrm{r}, \mathrm{a}, \mathrm{r}^{\prime}, \mathrm{a}^{\prime}, \mathrm{t}\right)=0$. 
Condition (ii) simply says that $\rho$ is a proportion. Condition (iii) states that the total number of pairs of $(r, a)$ individuals with $\left(r^{\prime}, a^{\prime}\right)$ individuals equals the total number of contacts of $\left(r^{\prime}, a^{\prime}\right)$ individuals with $(r, a)$ individuals (all this is per unit time, age, and time since infection). Condition (iv) says that there is no mixing in the age and activity levels where there are no active individuals; i.e., on the set

$$
S=\left\{\left(r, a, r^{\prime}, a^{\prime}\right): C(r, a, W(T(., ., t))) T(r, a, t) C\left(r^{\prime}, a^{\prime}, W(T(., ., t))\right) T\left(r^{\prime}, a^{\prime}, t\right)=0\right\}
$$

where there is no mixing. Condition (iv) arises naturally as will be seen in Section 4 , hence, we proceed to state our results without this assumption until it is required.

In some situations it is necessary to consider mixing functions $\rho$, which are Dirac delta functions (see BCC) or, more generally, distributions or generalized functions. Hence, we are forced to consider solutions to this axiomatic framework in the space of distributions or generalized functions (see Schwartz 1966 or Gel'fand and Shilov 1964). This is easily accomplished by choosing appropriate spaces of test functions whose generic elements we denote by $f$, and using the following modification to the interpretation of axioms (i) and (iv):

(i') $\rho \geq 0$ in the sense of distributions; i.e.,

$$
\int_{0}^{\infty} \int_{0}^{\infty} \rho\left(\mathrm{r}, \mathrm{a}, \mathrm{r}^{\prime}, \mathrm{a}^{\prime}\right) \mathrm{f}\left(\mathrm{r}^{\prime}, \mathrm{a}^{\prime}\right) \mathrm{dr^{ \prime }} \mathrm{da}^{\prime} \geq 0 \text { for all } \mathrm{f} \geq 0, \text { and }
$$

(iv') $\rho=0$ on a set $\mathrm{S}$, which means

$$
\iint_{S} \rho\left(r, a, r^{\prime}, a^{\prime}\right) f\left(r^{\prime}, a^{\prime}, r, a\right) d r^{\prime} d^{\prime} d r d a=0 \text { for all } \mathrm{f} .
$$

In writing the conditions characterizing $\rho$ we have exhibited their functional dependence on $\left(r, a, r^{\prime}, a^{\prime}\right)$ and, for notational convenience, have suppressed their dependence on $\mathrm{t}$ and $\mathrm{T}$.

Pair formations can involve selectivity by individuals according to age or activity level, they can be random pairings without regard to these variables, or they can be any combination or mixture of the two extremes. A detailed discussion of these possibilities and of the restrictions they place on the mixing function $\rho$ is found in Section 3. The effects of mixing on disease transmission can be modeled through the incidence rate (new infected cases per unit time) or the "force" of the infection. We begin by letting $\beta\left(\mathrm{r}, \mathrm{a}, \tau, \mathrm{r}^{\prime}, \mathrm{a}^{\prime}\right)$ denote the probability that a pairing between $\mathrm{a}\left(\mathrm{r}^{\prime}, \mathrm{a}^{\prime}, \tau\right)$ infective individual 
and an $(r, a)$ susceptible will lead to the passing of the infection to the susceptible (other interpretations are possible, see Castillo-Chavez et al. 1989d, e, Cooke et al. 1989), and by observing that I/T denotes the proportion of contacts of a susceptible with an infective individual. The force of infection term $\mathrm{B}$ is therefore given by the following expression:

$$
\mathrm{B}(\mathrm{r}, \mathrm{a}, \mathrm{t})=\mathrm{C}(\mathrm{r}, \mathrm{a}, \mathrm{W}(\mathrm{T}(\cdot, \cdot, \mathrm{t}))) \int_{0}^{\infty} \int_{0}^{\infty} \int_{0}^{\infty} \beta\left(\mathrm{r}, \mathrm{a}, \tau, \mathrm{r}^{\prime}, \mathrm{a}^{\prime}\right) \rho\left(\mathrm{r}, \mathrm{a}, \mathrm{r}^{\prime}, \mathrm{a}^{\prime}\right) \frac{\mathrm{I}\left(\mathrm{r}^{\prime}, \mathrm{a}^{\prime}, \tau, \mathrm{t}\right)}{\mathrm{T}\left(\mathrm{r}^{\prime}, \mathrm{a}^{\prime}, \mathrm{t}\right)} \mathrm{dr}^{\prime} \mathrm{da} \mathrm{a}^{\prime} \mathrm{d} \tau,
$$

and the incidence rate is given by $S(r, a, t) B(r, a, t)$. In order to simplify the notation we shall write $\mathrm{C}(\mathrm{r}, \mathrm{a}, \mathrm{W})$ for $\mathrm{C}(\mathrm{r}, \mathrm{a}, \mathrm{W}(\mathrm{T}(\cdot, \cdot, \mathrm{t})))$ in the argument that follows. The interpretation of the term is as follows: there are $\mathrm{S}(\mathrm{r}, \mathrm{a}, \mathrm{t}) \Delta \mathrm{r} \Delta \mathrm{a}$ susceptibles in the class interval $\Delta \mathrm{a} \times \Delta \mathrm{r}$, and those individuals have $\mathrm{S}(\mathrm{r}, \mathrm{a}, \mathrm{t}) \mathrm{C}(\mathrm{r}, \mathrm{a}, \mathrm{W}) \Delta \mathrm{r} \Delta \mathrm{a}$ contacts per unit time. Of these contacts $\mathrm{S}(\mathrm{r}, \mathrm{a}, \mathrm{t}) \mathrm{C}(\mathrm{r}, \mathrm{a}, \mathrm{W}) \rho\left(\mathrm{r}, \mathrm{a}, \mathrm{r}^{\prime}, \mathrm{a}^{\prime}\right) \Delta \mathrm{r} \Delta \mathrm{a}$ are with active individuals in the $\left(\mathbf{r}^{\prime}, \mathrm{a}^{\prime}\right)$ class, and a proportion

$$
\frac{\mathrm{I}\left(\mathbf{r}^{\prime}, \mathbf{a}^{\prime}, \tau, \mathrm{t}\right)}{\mathrm{T}\left(\mathbf{r}^{\prime}, \mathbf{a}^{\prime}, \mathbf{t}\right)}
$$

are with infective individuals. Thus the number of contacts per unit time of $(r, a)$ individuals with infectives in the $\left(\mathbf{r}^{\prime}, \mathbf{a}^{\prime}, \tau\right)$ class is

$$
\mathrm{S}(\mathrm{r}, \mathrm{a}, \mathrm{t}) \mathrm{C}(\mathrm{r}, \mathrm{a}, \mathrm{W}) \rho\left(\mathrm{r}, \mathrm{a}, \mathbf{r}^{\prime}, \mathrm{a}^{\prime}\right) \frac{\mathrm{I}\left(\mathbf{r}^{\prime}, \mathrm{a}^{\prime}, \tau, \mathrm{t}\right)}{\mathrm{T}\left(\mathbf{r}^{\prime}, \mathrm{a}^{\prime}, \mathrm{t}\right)} \Delta \mathrm{a} \Delta \mathrm{r}
$$

and therefore the expected rate of disease transmission due to such contacts with infectives in the $\Delta \times \Delta \mathbf{a}^{\prime} \times \Delta \mathbf{r}^{\prime}$ interval is

$$
\mathrm{S}(\mathrm{r}, \mathrm{a}, \mathrm{t}) \mathrm{C}(\mathrm{r}, \mathrm{a}, \mathrm{W}) \beta\left(\mathrm{r}, \mathrm{a}, \tau, \mathrm{r}^{\prime}, \mathrm{a}^{\prime}\right) \rho\left(\mathrm{r}, \mathrm{a}, \mathrm{r}^{\prime}, \mathrm{a}^{\prime}\right) \frac{\mathrm{I}\left(\mathrm{r}^{\prime}, \mathrm{a}^{\prime}, \tau, \mathrm{t}\right)}{\mathrm{T}\left(\mathrm{r}^{\prime}, \mathrm{a}^{\prime}, \mathrm{t}\right)} \Delta \mathrm{a}^{\prime} \Delta \mathrm{r}^{\prime} \Delta \tau \Delta \mathrm{a} \Delta \mathrm{r}
$$

To find all the disease transmission contacts between susceptibles in the $\Delta a \times \Delta r$ interval with all possible infectives, we sum over $\Delta \tau \times \Delta \mathrm{a}^{\prime} \times \Delta \mathrm{r}^{\prime}$ to get $\mathrm{B}(\mathrm{r}, \mathrm{a}, \mathrm{t})$. Note that the dynamics implied for the susceptible class are given by

$$
\frac{\partial \mathrm{S}}{\partial \mathrm{t}}(\mathrm{r}, \mathrm{a}, \mathrm{t})+\frac{\partial \mathrm{S}}{\partial \mathrm{a}}(\mathrm{r}, \mathrm{a}, \mathrm{t})+\mu(\mathrm{r}, \mathrm{a}, \mathrm{t}) \mathrm{S}(\mathrm{r}, \mathrm{a}, \mathrm{t})=\Lambda(\mathrm{r}, \mathrm{a}, \mathrm{t}, \mathrm{T}(\mathrm{a}, \mathrm{r}, \mathrm{t}))-\mathrm{B}(\mathrm{r}, \mathrm{a}, \mathrm{t}),
$$

where $\Lambda$ denotes the "recruitment" rate into the susceptible class, and $\mu$ denotes the natural per capita removable rate from sexual activity (due to all causes except severe symptoms or "full-blown" AIDS). We observe that there are several constitutive forms of the interaction term $\rho$; examples without age structure can be found in BCC. Tables Ia and Ib illustrate several possibilities, for age- 
and activity-dependent mixing. These nine general cases include proportionate mixing in the age variable only, proportionate mixing in the activity variable only, and proportionate mixing in both age and activity variables. One of the simplest forms of mixing is that of proportionate or random mixing which in our present framework includes both variables of age and activity level. It is given by a generalization of the model used for situations without age-structure by May and Anderson (1989):

$$
\bar{\rho}\left(r, a, r^{\prime}, a^{\prime}, t\right)=\frac{C\left(r^{\prime}, a^{\prime}, W(T(., ., t))\right) T\left(r^{\prime}, a^{\prime}, t\right)}{\int_{0}^{\infty} \int_{0}^{\infty} C\left(r^{\prime}, a^{\prime}, W(T(., ., t)) T\left(r^{\prime}, a^{\prime}, t\right) d a^{\prime} d r^{\prime}\right.}, \text { if }\left(r, a, r^{\prime}, a^{\prime}\right) \notin S
$$

and $\bar{\rho}\left(\mathrm{r}, \mathrm{a}, \mathrm{r}^{\prime}, \mathrm{a}^{\prime}, \mathrm{t}\right)=0$ if $\left(\mathrm{r}, \mathrm{a}, \mathrm{r}^{\prime}, \mathrm{a}^{\prime}\right) \in \mathrm{S}$. This solution plays an important role in the determination of all possible solutions to the mixing framework (i)-(iv). As will be shown in the next section, all mixing functions are multiplicative perturbations of proportional mixing. Note that proportionate mixing vacuously satisfies condition (iv). This condition prevents us from arbitrarily defining a mixing function for subpopulations that either are not sexually active or that have been depleted of individuals by disease dynamics.

\section{Mixing dependent incidence rates}

From Equation 1, it is evident that the incidence rate is affected by two parameters: the infectivity and the mixing function. In this section we begin to analyze the role of mixing in disease dynamics by discussing some specific constitutive forms for the mixing function $\rho$ (for a preliminary mathematical analysis of the effects of variable infectivity, see Thieme and Castillo-Chavez 1989a, b). The objective of this Section is to illustrate nine general cases that may be useful for modeling purposes. We hope that our brief classification may be of use by making clear the assumptions behind the choice of each mixing function. In the next section we present a representation theorem that includes all possible solutions to axioms (i)-(iv), and that therefore contains the solutions in this section, although not always in a transparent way. In giving these expressions we assume, for simplicity, that $\mathrm{C}$ does not depend on $\mathrm{W}$, and do not repeat the condition that $\rho$ vanished on the set S. 
(I) Proportionate mixing in the age variable only. Individuals in the $(r, a)$ class, when choosing partners, do not show preference for any age group. Consequently, as far as age is concerned, pair formation is a stratified random process. Thus the proportion of contacts of an $(r, a)$ individual (per capita of active population) with $\left(\mathbf{r}^{\prime}, \mathrm{a}^{\prime}\right)$ individuals is of the form

$$
\rho\left(\mathrm{r}, \mathrm{a}, \mathrm{r}^{\prime}, \mathrm{a}^{\prime}\right) \mathrm{C}(\mathrm{r}, \mathrm{a})=\tilde{\rho}\left(\mathrm{r}, \mathrm{a}, \mathrm{r}^{\prime}\right) \mathrm{C}(\mathrm{r}, \mathrm{a}) \frac{\mathrm{C}\left(\mathrm{r}^{\prime}, \mathrm{a}^{\prime}\right) \mathrm{T}\left(\mathrm{r}^{\prime}, \mathrm{a}^{\prime}\right)}{\int_{0}^{\infty} \mathrm{C}\left(\mathrm{r}^{\prime}, \mathrm{a}^{\prime}\right) \mathrm{T}\left(\mathrm{r}^{\prime}, \mathrm{a}^{\prime}\right) \mathrm{da} \mathrm{a}^{\prime}} ;
$$

that is, contact with age $\mathbf{a}^{\prime}$ individuals is directly related to the proportion of the activity level of such individuals in the total active population across all age groups. This proportion at time $t$ is, of course,

$$
\frac{C\left(r^{\prime}, a^{\prime}\right) T\left(r^{\prime}, a^{\prime}, t\right)}{\int_{0}^{\infty} C\left(r^{\prime}, a^{\prime}\right) T\left(r^{\prime}, a^{\prime}, t\right) d a^{\prime}}
$$

The force of infection term becomes

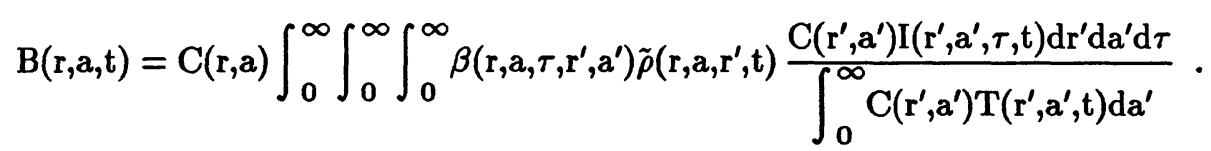

Remark: Note that because of the presence of the activity level variable, the integral in the denominator cannot be taken out of the triple integral.

Using the same type of reasoning as in (I) we obtain the following acceptable forms for the mixing function $\rho$ :

(II) Proportionate mixing in the activity variable only.

$$
\rho\left(r, a, r^{\prime}, a^{\prime}\right)=\tilde{\rho}\left(r, a, a^{\prime}\right) \frac{C\left(r^{\prime}, a^{\prime}\right) T\left(r^{\prime}, a^{\prime}\right)}{\int_{0}^{\infty} C\left(r^{\prime}, a^{\prime}\right) T\left(r^{\prime}, a^{\prime}\right) d r^{\prime}} .
$$

(III) Proportionate mixing in both the age and partner variables.

$$
\rho\left(r, a, r^{\prime}, a^{\prime}\right)=\tilde{\rho}(r, a) \frac{C\left(r^{\prime}, a^{\prime}\right) T\left(r^{\prime}, a^{\prime}\right)}{\int_{0}^{\infty} \int_{0}^{\infty} C\left(r^{\prime}, a^{\prime}\right) T\left(r^{\prime}, a^{\prime}\right) d a^{\prime} d r^{\prime}} .
$$

(I)-(III) assume that the persons selecting partners have criteria of selection which depend on the class to which they belong. We now turn to situations where that is not the case. 
(IV) Uniform age selectivity .

$$
\rho\left(\mathbf{r}, \mathbf{a}, \mathbf{r}^{\prime}, \mathbf{a}^{\prime}\right)=\tilde{\rho}\left(\mathbf{r}, \mathbf{r}^{\prime}, \mathbf{a}^{\prime}\right),
$$

here we assume that individuals in the $(r, a)$ class have the same selection criteria as individuals in any other $\left(r, a^{*}\right)$ class, $a^{*} \in[0, \infty)$; i.e., selection is independent of the age of the individual who is selecting; however, it does depend on the age of those who are being selected as partners.

(V) Uniform activity selectivity.

$$
\rho\left(r, a, r^{\prime}, a^{\prime}\right)=\tilde{\rho}\left(a, r^{\prime}, a^{\prime}\right)
$$

here the activity level of the individual does not affect his/her selectivity criteria.

(VI) Uniform age and activity selectivity.

$$
\rho\left(\mathrm{r}, \mathrm{a}, \mathrm{r}^{\prime}, \mathrm{a}^{\prime}\right)=\tilde{\rho}\left(\mathbf{r}^{\prime}, \mathrm{a}^{\prime}\right)
$$

We can combine (I) - (III) with (IV) - (VI) in various ways and obtain nine different forms for the mixing function function $\rho$, which we exhibit on Tables Ia and Ib together with the resulting form of the force of infection which is obtained from (1). We also list the restrictions placed in $\tilde{\rho}$ and $\mathrm{C}$ by (ii) and (iii). Even though we are singling out these nine possible versions at this stage, the general form of $\rho$ needs to only satisfy conditions (i) - (ii) - (iii), and each of the special cases involves a constitutive assumption concerning the mode of mixing and partner selection. We also note that both $\rho$ and $\mathrm{C}$ may be density-dependent, and we are beginning to look at such extensions (see CastilloChavez et al. 1989e, and Thieme and Castillo-Chavez 1989a, b) . Finally we observe that convex linear combinations of mixing functions are mixing functions. Specifically, if $\alpha_{1}, \ldots \alpha_{N}$ are positive constants such that $\sum_{i=1}^{N} \alpha_{i}=1$ and $\rho_{1}, \ldots, \rho_{N}$ are mixing functions, then $\sum_{i=1}^{N} \alpha_{i} \rho_{i}$ is a mixing function. This last observation provides a recipe for the construction of a variety of mixing functions; furthermore, it clearly shows that preferred mixing (a convex combination of two mixing functions), contrary to the suggestions of some researchers, does not contain all reasonable possibilities. Specifically, (omitting age) preferred mixing is given by

$$
\rho(\mathrm{s}, \mathrm{r})=(1-\alpha) \frac{\mathrm{C}(\mathrm{r}) \mathrm{T}(\mathrm{r})}{\int_{0}^{\infty} \mathrm{C}(\mathrm{u}) \mathrm{T}(\mathrm{u}) \mathrm{du}}+\alpha \delta(\mathrm{s}-\mathrm{r})
$$


where $\delta$ denotes the Dirac delta (see BCC), i.e., it is the convex linear combination of the Dirac delta (a mixing function) and proportionate mixing. The two extreme points of this particular convex linear combination (when $\alpha=0$ or 1 ) do not obviously represent sociological or mathematical mixing extremes - this was pointed out to us by S. Gupta and R. Anderson--as some researchers have suggested.

We now show how to recover the case of no age-dependence which yields the original formalism of BCC. To circumvent the fact that we cannot eliminate the variables $\left(a, a^{\prime}\right)$ in $\rho$ because (i) and (ii) are then incomparable, we need to assume that the population is not age-structured, hence $T(r, a) \equiv T(r)$ does not depend on a. We further assume that there is a maximum age $A$, and that $\rho\left(\mathrm{r}, \mathrm{a}, \mathrm{r}^{\prime}, \mathrm{a}^{\prime}\right)=\mathbf{0}$ if $\mathrm{a}>\mathrm{A}$, or $\mathrm{a}^{\prime}>\mathrm{A}$, and set

$$
\rho\left(\mathrm{r}, \mathrm{a}, \mathrm{r}^{\prime}, \mathrm{a}^{\prime}\right)=\left\{\begin{array}{cc}
0, & \text { if } \mathrm{a}>\mathrm{A} \text { or } \mathrm{a}^{\prime}>\mathrm{A} \\
\frac{1}{\mathrm{~A}} \rho\left(\mathrm{r}, \mathrm{r}^{\prime}\right), \text { with } \int_{0}^{\infty} \rho\left(\mathrm{r}, \mathrm{r}^{\prime}\right) \mathrm{d} \mathbf{r}^{\prime}=1, & \rho\left(\mathrm{r}, \mathrm{r}^{\prime}\right) \geq 0, \text { otherwise }
\end{array} .\right.
$$

Conditions (i) and (ii) are then automatically satisfied, (iii) becomes

$$
\rho\left(\mathrm{r}, \mathrm{r}^{\prime}\right) \mathrm{C}(\mathrm{r}) \mathrm{T}(\mathrm{r})=\rho\left(\mathrm{r}^{\prime}, \mathbf{r}\right) \mathrm{C}\left(\mathrm{r}^{\prime}\right) \mathrm{T}\left(\mathrm{r}^{\prime}\right),
$$

and we recapture the conditions of BCC. The force of infection term now becomes

$$
\mathrm{B}(\mathrm{r}, \mathrm{t})=\mathrm{S}(\mathrm{r}, \mathrm{t}) \mathrm{C}(\mathrm{r}) \int_{0}^{\infty} \int_{0}^{\infty} \beta\left(\mathrm{r}, \tau, \mathbf{r}^{\prime}\right) \rho\left(\mathrm{r}, \mathbf{r}^{\prime}, \mathrm{t}\right) \frac{\mathrm{I}\left(\mathbf{r}^{\prime}, \tau, \mathrm{t}\right)}{\mathrm{T}\left(\mathbf{r}^{\prime}, \mathrm{t}\right)} \mathrm{dr} \mathrm{r}^{\prime} \mathrm{d} \tau
$$

If $\beta$ is independent of $\tau$, we can integrate $\mathrm{I}\left(\mathrm{r}^{\prime}, \tau, \mathrm{t}\right)$ over $\tau$ to get

$$
\mathrm{B}(\mathrm{r}, \mathrm{t})=\mathrm{S}(\mathrm{r}, \mathrm{t}) \mathrm{C}(\mathrm{r}) \int_{0}^{\infty} \beta\left(\mathrm{r}, \mathrm{r}^{\prime}\right) \rho\left(\mathrm{r}, \mathrm{r}^{\prime}\right) \frac{\mathrm{I}\left(\mathrm{r}^{\prime}, \mathrm{t}\right)}{\mathrm{T}\left(\mathrm{r}^{\prime}, \mathrm{t}\right)} \mathrm{dr}
$$

where we write $I\left(r^{\prime}, t\right)$ for $\int_{0}^{\infty} I\left(r^{\prime}, \tau, t\right) d \tau$. This is the form of the force of infection term used by BCC.

In combining the special cases I-II-III with IV-V-VI we need to avoid conflicting situations. In particular, we cannot have both I and IV or VI holding, and we cannot have II and V or VI holding. However, we can have I and V, and II and IV holding. There are strong conditions placed on $\tilde{\rho}$ in I or II by the additional hypotheses V or IV. For I and V we get $\tilde{\rho}=\tilde{\rho}\left(\mathrm{a}, \mathrm{r}^{\prime}\right)$, and using condition (iii) we must have $\tilde{\rho}=\tilde{\rho}\left(\mathrm{r}^{\prime}\right)$ only. One solution for $\tilde{\rho}$ is then

$$
\tilde{\rho}\left(\mathrm{r}^{\prime}\right)=\frac{\int_{0}^{\infty} \mathrm{C}\left(\mathbf{r}^{\prime}, \mathrm{a}^{\prime}\right) \mathrm{T}\left(\mathbf{r}^{\prime}, \mathbf{a}^{\prime}, \mathrm{t}\right) \mathrm{d \mathbf {a } ^ { \prime }}}{\int_{0}^{\infty} \int \mathrm{C}\left(\mathrm{r}^{\prime}, \mathrm{a}^{\prime}\right) \mathrm{T}\left(\mathrm{r}^{\prime}, \mathrm{a}^{\prime}, \mathrm{t}\right) \mathrm{d} \mathbf{r}^{\prime} \mathbf{d} \mathbf{a}^{\prime}} .
$$


Conditions (ii) and (iii) are then automatically satisfied. The force of infection term becomes

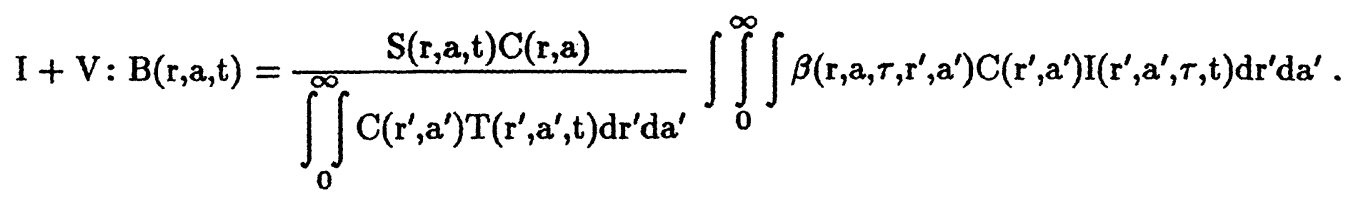

Similarly, from II + IV we get $\tilde{\rho}=\tilde{\rho}\left(\mathrm{a}^{\prime}\right)$ only, and one solution for $\tilde{\rho}$ then is

$$
\tilde{\rho}\left(\mathrm{a}^{\prime}\right)=\frac{\int_{0}^{\infty} \mathrm{C}\left(\mathrm{r}^{\prime}, \mathrm{a}^{\prime}\right) \mathrm{T}\left(\mathrm{r}^{\prime}, \mathrm{a}^{\prime}, \mathrm{t}\right) \mathrm{d \mathbf {r } ^ { \prime }}}{\int_{0}^{\infty} \int_{0} \mathrm{C}\left(\mathrm{r}^{\prime}, \mathrm{a}^{\prime}\right) \mathrm{T}\left(\mathbf{r}^{\prime}, \mathrm{a}^{\prime}, \mathrm{t}\right) \mathrm{dr^{ \prime }} \mathrm{da} \mathbf{a}^{\prime}}
$$

with force of infection term

$$
\mathrm{II}+\mathrm{V}: \mathrm{B}(\mathrm{r}, \mathrm{a}, \mathrm{t})=\frac{\mathrm{S}(\mathrm{r}, \mathrm{a}, \mathrm{t}) \mathrm{C}(\mathrm{r}, \mathrm{a})}{\iint_{0}^{\infty} \mathrm{C}\left(\mathrm{r}^{\prime}, \mathrm{a}^{\prime}\right) \mathrm{T}\left(\mathrm{r}^{\prime}, \mathrm{a}^{\prime}, \mathrm{t}\right) \mathrm{dr^{ \prime } d \mathrm { a } ^ { \prime }}} \iint_{0}^{\infty} \int \beta\left(\mathrm{r}, \mathrm{a}, \tau, \mathbf{r}^{\prime}, \mathrm{a}^{\prime}\right) \mathrm{C}\left(\mathrm{r}^{\prime}, \mathrm{a}^{\prime}\right) \mathrm{I}\left(\mathbf{r}^{\prime}, \mathrm{a}^{\prime}, \tau, \mathrm{t}\right) \mathrm{dr} \mathrm{r}^{\prime} \mathrm{da} \mathrm{a}^{\prime} \mathrm{d} \tau,
$$

which is identical to that obtained for $\mathrm{I}+\mathrm{V}$.

\section{General form of the Interaction Term}

In the previous section several special forms of the interaction term $\rho$ were derived on the basis of constitutive assumptions concerning the pair formation mechanism. Here we pursue another path and examine the mathematical implications of the conditions (i)-(iv) on $\rho$. We will derive the general form of $\rho$ and, in the process, also show that the particular forms of $\rho$ that we discussed in the previous section enjoy certain special mathematical properties. The relations that we derive for $\rho$ will allow us to construct a variety of different mixing/pairing functions without having to return to the basic axioms (i)-(iv).

Recall that one solution of (i)-(iv) is given by the total proportionate-mixing pairing function $\rho=\bar{\rho}$, where for $\left(\mathrm{r}, \mathrm{a}, \mathrm{r}^{\prime}, \mathrm{a}\right) \notin \mathrm{S}$,

$$
\bar{\rho}\left(r, a, r^{\prime}, \mathbf{a}^{\prime}, t\right)=\frac{C\left(r^{\prime}, \mathbf{a}^{\prime}\right) T\left(\mathbf{r}^{\prime}, \mathbf{a}^{\prime}, t\right)}{\int_{0}^{\infty} \int(u, v) T(u, v, t) d u d v} .
$$

Since the expression $C(r, a) T(r, a, t)$ will appear often in our computations, and since it can be treated as a parameter only, we use the simplified notation 


$$
f(r, a)=C(r, a) T(r, a, t),
$$

where the variable $t$ is suppressed in $f$ for notational convenience. Thus, from (5),

$$
\bar{\rho}\left(r, a, r^{\prime}, a^{\prime}\right)=\frac{f\left(r^{\prime}, a^{\prime}\right)}{\iint_{0}^{\infty} f(u, v) d u d v} .
$$

A useful relation which is obtained by integrating (iii) over the variables $\mathbf{r}^{\prime}$ and $\mathbf{a}^{\prime}$ and using condition (ii):

which we can also write as

$$
\mathrm{C}(\mathrm{r}, \mathrm{a}) \mathrm{T}(\mathrm{r}, \mathrm{a}, \mathrm{t})=\int_{0}^{\infty} \int_{0} \rho\left(\mathrm{r}^{\prime}, \mathrm{a}^{\prime}, \mathrm{r}, \mathrm{a}\right) \mathrm{C}\left(\mathrm{r}^{\prime}, \mathrm{a}^{\prime}\right) \mathrm{T}\left(\mathrm{r}^{\prime}, \mathrm{a}^{\prime}, \mathrm{t}\right) \mathrm{dr^{ \prime }} \mathrm{da^{ \prime }},
$$

$$
\mathrm{f}(\mathrm{r}, \mathrm{a})=\int_{0}^{\infty} \int_{0}^{\infty} \rho\left(\mathrm{r}^{\prime}, \mathrm{a}^{\prime}, \mathrm{r}, \mathrm{a}\right) \mathrm{f}\left(\mathrm{r}^{\prime}, \mathrm{a}^{\prime}\right) \mathrm{dr} \mathrm{r}^{\prime} \mathrm{da} \mathbf{a}^{\prime}
$$

A mixing function $\rho$ is called separable if it can be written in the form

$$
\rho\left(\mathrm{r}, \mathrm{a}, \mathrm{r}^{\prime}, \mathrm{a}^{\prime}\right)=\rho_{1}(\mathrm{r}, \mathrm{a}) \rho_{2}\left(\mathrm{r}^{\prime}, \mathrm{a}^{\prime}\right) .
$$

The total proportionate mixing function $\bar{\rho}$ is separable, and our first result shows that there are no other separable mixing/pairing functions. Although the proof of this result has appeared in Busenberg and Castillo-Chavez (1989) it is repeated here, as proportionate mixing plays a fundamental role in our analysis.

Theorem 4.1 The only separable mixing function $\rho$ satisfying conditions (i)-(iv) is the total proportionate mixing function $\bar{\rho}$ given by (5).

Proof: Suppose that $\rho$ is given by (10). Then from (ii), outside the set $S$, w have

$$
\rho_{1}(\mathrm{r}, \mathrm{a})=\frac{1}{\iint_{0}^{\infty} \rho_{2}\left(\mathrm{r}^{\prime}, \mathrm{a}^{\prime}\right) \mathrm{dr}^{\prime} \mathrm{da}^{\prime}}=\mathrm{k}, \mathrm{a} \text { constant }
$$

and therefore $\rho\left(r, a, r^{\prime}, a^{\prime}\right)=k \rho_{2}\left(r^{\prime}, a^{\prime}\right)$. Substituting this in (9) we obtain

Hence,

$$
f(r, a)=k \rho_{2}(r, a) \int_{0}^{\infty} \int_{0}^{f}\left(r^{\prime}, a^{\prime}\right) d r^{\prime} d a^{\prime}
$$

$$
\mathrm{k} \rho_{2}(\mathrm{r}, \mathrm{a})=\frac{\mathrm{f}(\mathrm{r}, \mathrm{a})}{\int_{\mathrm{C}}^{\infty} \int_{\mathrm{f}} \mathrm{f}\left(\left(\mathrm{r}^{\prime}, \mathrm{a}^{\prime}\right) \mathrm{dr}^{\prime} \mathrm{da}^{\prime}\right.}
$$


that is, $\rho=\bar{\rho}$. Since we have already shown that $\bar{\rho}$ satisfies (i)-(ii)-(iii) (and, incidentally, it vacuously satisfies (iv)), the proof is complete.

The next lemma will help in the construction of general mixing function $\rho$.

Lemma 4.2. The general solution $\rho$ of (i)-(ii)-(iii) has the form

$$
\rho\left(\mathrm{r}, \mathrm{a}, \mathrm{r}^{\prime}, \mathrm{a}^{\prime}\right)=\bar{\rho}\left(\mathrm{r}^{\prime}, \mathrm{a}^{\prime}\right)+\phi\left(\mathrm{r}, \mathrm{a}, \mathrm{r}^{\prime}, \mathrm{a}^{\prime}\right)
$$

where $\phi$ satisfies

$$
\begin{aligned}
& \phi Z-\bar{\rho} ; \quad \int_{0}^{\infty} \int_{0} \phi\left(\mathrm{r}, \mathrm{a}, \mathbf{r}^{\prime}, \mathrm{a}^{\prime}\right) \mathrm{dr} \mathrm{r}^{\prime} \mathrm{da}=0 ; \int_{0}^{\infty} \int_{0}^{\infty} \phi\left(\mathrm{r}^{\prime}, \mathrm{a}^{\prime}, \mathrm{r}, \mathrm{a}\right) \mathrm{f}\left(\mathbf{r}^{\prime}, \mathrm{a}^{\prime}\right) \mathrm{dr} \mathrm{r}^{\prime} \mathrm{da}^{\prime}=0 \\
& \phi\left(r, a, r^{\prime}, a^{\prime}\right) f(r, a)=\phi\left(r^{\prime}, a^{\prime}, r, a\right) f\left(r^{\prime}, a^{\prime}\right) .
\end{aligned}
$$

Proof: These properties of $\phi$ follow easily by substituting the form (11) into (i), (ii), (iii), and (7) and using the fact that both $\rho$ and $\bar{\rho}$ must satisfy these relations.

The next result gives us a general representation formula for the mixing function $\rho$.

Theorem 4.3. Let $\phi\left(r, a, r^{\prime}, a^{\prime}\right) \geq 0$, be symmetric in the $(r, a)$ and $\left(r^{\prime}, a^{\prime}\right)$ variables, $\phi\left(r, a, r^{\prime}, a^{\prime}\right)=\phi\left(r^{\prime}, a^{\prime}, r, a\right)$, and $\int_{0}^{\infty} \int \bar{\rho}\left(r^{\prime}, a^{\prime}\right) \phi\left(r, a, r^{\prime}, a^{\prime}\right) d r^{\prime} d a^{\prime}=1$. Then

$$
\rho\left(\mathbf{r}, \mathbf{a}, \mathbf{r}^{\prime}, \mathbf{a}^{\prime}\right)=\bar{\rho}\left(\mathbf{r}^{\prime}, \mathrm{a}^{\prime}\right) \phi\left(\mathrm{r}, \mathrm{a}, \mathbf{r}^{\prime}, \mathrm{a}^{\prime}\right)
$$

is a mixing function. Conversely, every mixing function $\rho$ is given by the form (13), where $\phi$ is symmetric and satisfies the hypotheses of the theorem.

Proof: Suppose that $\phi$ satisfies the hypotheses and $\rho$ is given by (13). Then it is clear that $\rho \geq 0$, so (i) holds. Also (ii) holds automatically. Finally,

$$
\begin{aligned}
\rho\left(\mathrm{r}, \mathrm{a}, \mathrm{r}^{\prime}, \mathrm{a}^{\prime}\right) \mathrm{f}(\mathrm{r}, \mathrm{a}) & =\bar{\rho}\left(\mathrm{r}^{\prime}, \mathrm{a}^{\prime}\right) \phi\left(\mathrm{r}, \mathrm{a}, \mathrm{r}^{\prime}, \mathrm{a}^{\prime}\right) \mathrm{f}(\mathrm{r}, \mathrm{a}) \\
& =\bar{\rho}\left(\mathrm{r}^{\prime}, \mathrm{a}^{\prime}\right) \phi\left(\mathrm{r}, \mathrm{a}, \mathrm{r}^{\prime}, \mathrm{a}^{\prime}\right) \bar{\rho}(\mathrm{r}, \mathrm{a}) \int_{0}^{\infty} \int_{0} \mathrm{f}(\mathrm{r}, \mathrm{a}) \mathrm{drda} \\
& =\bar{\rho}(\mathrm{r}, \mathrm{a}) \phi\left(\mathrm{r}^{\prime}, \mathrm{a}^{\prime}, \mathrm{r}, \mathrm{a}\right) \bar{\rho}\left(\mathrm{r}^{\prime}, \mathrm{a}^{\prime}\right) \int_{0}^{\infty} \int_{0} \mathrm{f}(\mathrm{r}, \mathrm{a}) \mathrm{drda} \\
& =\bar{\rho}\left(\mathrm{r}^{\prime}, \mathrm{a}^{\prime}, \mathrm{r}, \mathrm{a}\right) \mathbf{f}\left(\mathrm{r}^{\prime}, \mathrm{a}^{\prime}\right),
\end{aligned}
$$

hence (iii) holds. 
Conversely, let $\rho$ be an arbitrary mixing function and let

$$
\phi\left(\mathrm{r}, \mathrm{a}, \mathbf{r}^{\prime}, \mathrm{a}^{\prime}\right)=\left\{\begin{array}{c}
0 \text { if } \bar{\rho}\left(\mathbf{r}^{\prime}, \mathrm{a}^{\prime}\right)=0 \\
\rho\left(\mathbf{r}, \mathbf{a}, \mathbf{r}^{\prime}, \mathrm{a}^{\prime}\right) / \bar{\rho}\left(\mathbf{r}^{\prime}, \mathrm{a}^{\prime}\right), \text { otherwise }
\end{array} .\right.
$$

Note that $\rho\left(r, a, r^{\prime}, a^{\prime}\right)$ vanishes outside the support of $f(r, a) f\left(r^{\prime}, a^{\prime}\right)$ by property IV; hence, it vanishes where $\bar{\rho}\left(\mathbf{r}^{\prime}, \mathbf{a}^{\prime}\right)=0$. Then by (iii),

$$
\begin{aligned}
& \rho\left(\mathrm{r}, \mathrm{a}, \mathbf{r}^{\prime}, \mathrm{a}^{\prime}\right) \mathrm{f}(\mathrm{r}, \mathrm{a})=\bar{\rho}\left(\mathrm{r}^{\prime}, \mathrm{a}^{\prime}\right) \phi\left(\mathrm{r}, \mathrm{a}, \mathrm{r}^{\prime}, \mathrm{a}^{\prime}\right) \mathrm{f}(\mathrm{r}, \mathrm{a})=\rho\left(\mathrm{r}^{\prime}, \mathrm{a}^{\prime}, \mathrm{r}, \mathrm{a}\right) \mathrm{f}\left(\mathrm{r}^{\prime}, \mathrm{a}^{\prime}\right) \\
& =\bar{\rho}(\mathrm{r}, \mathrm{a}) \phi\left(\mathrm{r}^{\prime}, \mathrm{a}^{\prime}, \mathrm{r}, \mathrm{a}\right) \mathrm{f}\left(\mathrm{r}^{\prime}, \mathrm{a}^{\prime}\right) .
\end{aligned}
$$

Hence, $\phi\left(r, a, r^{\prime}, a^{\prime}\right)=\phi\left(r^{\prime}, a^{\prime}, r, a\right)$ since $\bar{\rho}\left(r^{\prime}, a^{\prime}\right) f(r, a)=\bar{\rho}(r, a) f\left(r^{\prime}, a^{\prime}\right)$. Thus $\phi$ must by symmetric. Clearly, $\phi \geq 0$ by (i), and outside $S$,

$$
\int_{0}^{\infty} \int_{0} \phi\left(\mathrm{r}, \mathrm{a}, \mathrm{r}^{\prime}, \mathrm{a}^{\prime}\right) \bar{\rho}\left(\mathrm{r}^{\prime}, \mathrm{a}^{\prime}\right) \mathrm{d} \mathrm{r}^{\prime} \mathrm{da} \mathrm{a}^{\prime}=\int_{0}^{\infty} \int_{0} \rho\left(\mathrm{r}, \mathrm{a}, \mathrm{r}^{\prime}, \mathrm{a}^{\prime}\right) \mathrm{dr^{ \prime }} \mathrm{da}^{\prime}=1 .
$$

This completes the proof.

Thus, in the construction of mixing functions, we seek to find non-negative symmetric functions which satisfy the integral condition in the hypotheses of the theorem. These symmetric functions are arbitrary except for this integral condition. Since we already have found several special forms for the mixing function $\rho$, we might seek an explicit formula allowing us to construct arbitrary mixing functions as perturbations of particularly convenient special forms. We will proceed to give such a representation. We start by noting that condition (iii) on $\rho$ can be written as

$$
\rho\left(\mathrm{r}, \mathrm{a}, \mathrm{r}^{\prime}, \mathrm{a}^{\prime}\right) \bar{\rho}(\mathrm{r}, \mathrm{a})=\rho\left(\mathrm{r}^{\prime}, \mathrm{a}^{\prime}, \mathrm{r}, \mathrm{a}\right) \bar{\rho}\left(\mathrm{r}^{\prime}, \mathrm{a}^{\prime}\right) .
$$

Letting supp $\bar{\rho}=\left\{(r, a) \in \mathfrak{B}_{+}^{2}: \bar{\rho}(\mathrm{r}, \mathrm{a})>0\right\}$, we note that for all $\left(\mathrm{r}^{\prime}, \mathrm{a}^{\prime}\right), \rho\left(\mathrm{r}^{\prime}, \mathrm{a}^{\prime}, \mathbf{r}, \mathrm{a}\right) \bar{\rho}\left(\mathrm{r}^{\prime}, \mathrm{a}^{\prime}\right)=0$ if $(\mathrm{r}, \mathrm{a}) \notin \operatorname{supp} \bar{\rho}$ and $\rho\left(\mathrm{r}, \mathrm{a}, \mathrm{r}^{\prime}, \mathrm{a}^{\prime}\right) \bar{\rho}(\mathrm{r}, \mathrm{a})=\mathbf{0}$ for all $(\mathrm{r}, \mathrm{a})$ when $\left(\mathrm{r}^{\prime}, \mathrm{a}^{\prime}\right) \notin \operatorname{supp} \bar{\rho}$. Thus, supp $\rho=\left\{\left(\mathrm{r}, \mathrm{a}, \mathrm{r}^{\prime}, \mathrm{a}^{\prime}\right) \in \mathscr{R}_{+}^{4}: \rho\left(\mathrm{r}, \mathrm{a}, \mathrm{r}^{\prime}, \mathrm{a}^{\prime}\right)>0\right\}$, and the set

$$
\begin{array}{r}
S=\left\{\left(r, a, r^{\prime}, a^{\prime}\right):(r, a) \notin \operatorname{supp} \bar{\rho} \text { and }\left(r^{\prime}, a^{\prime}\right) \notin \operatorname{supp} \bar{\rho} ;\right. \text { or } \\
\left.(r, a) \notin \operatorname{supp} \bar{\rho} \text { and }\left(r^{\prime}, a^{\prime}\right) \notin \operatorname{supp} \bar{\rho}\right\}
\end{array}
$$

satisfy

$$
\operatorname{supp} \rho \cap \mathrm{S}=\phi .
$$

However, in the context of our model, $\rho$ can be assigned arbitrary non-negative values on the set $\tilde{\mathrm{S}}=\left\{\left(\mathrm{r}, \mathrm{a}, \mathrm{r}^{\prime}, \mathrm{a}^{\prime}\right):(\mathrm{r}, \mathrm{a}) \notin \operatorname{supp} \bar{\rho}\right.$ and $\left.\left(\mathrm{r}^{\prime}, \mathrm{a}^{\prime}\right) \notin \operatorname{supp} \bar{\rho}\right\}$, since the activity level $\mathrm{f}=\mathrm{cT}$ is zero on $\tilde{\mathrm{S}}$. 
Thus, we can normalize $\rho$, without loss of generality, by requiring the following condition in addition to (i), (ii), and (iii):

$$
\operatorname{supp} \rho \subset\left\{\left(\mathrm{r}, \mathrm{a}, \mathrm{r}^{\prime}, \mathrm{a}^{\prime}\right):(\mathrm{r}, \mathrm{a}) \in \operatorname{supp} \bar{\rho} \text { and }\left(\mathrm{r}^{\prime}, \mathrm{a}^{\prime}\right) \in \operatorname{supp} \bar{\rho}\right\} \equiv \mathcal{A}
$$

Clearly, from (iv), $\rho\left(\mathrm{r}, \mathrm{a}, \mathrm{r}^{\prime}, \mathrm{a}^{\prime}\right)=0$ if either $\bar{\rho}(\mathrm{r}, \mathrm{a})=0$ or $\bar{\rho}\left(\mathrm{r}^{\prime}, \mathrm{a}^{\prime}\right)=0$. Henceforth, our mixing functions will satisfy (i) - (iv). These observations, together with the additional condition (iv), gives a useful representation formula for any mixing function $\rho$.

Theorem 4.4. Let $\phi: \mathscr{B}_{+}^{4} \rightarrow \Re_{B}$ be measurable and jointly symmetric: $\phi\left(\mathrm{r}, \mathrm{a}, \mathrm{r}^{\prime}, \mathrm{a}^{\prime}\right)=\phi\left(\mathrm{r}^{\prime}, \mathrm{a}^{\prime}, \mathrm{r}, \mathrm{a}\right)$, and suppose that

$$
\int_{0}^{\infty} \int^{\infty} \bar{\rho}\left(\mathbf{r}^{\prime}, \mathbf{a}^{\prime}\right) \phi\left(\mathbf{r}, \mathbf{a}, \mathbf{r}^{\prime}, \mathrm{a}^{\prime}\right) \mathrm{dr} \mathbf{r}^{\prime} \mathrm{da} \mathbf{a}^{\prime} \leq 1
$$

and

$$
\int_{0}^{\infty} \int_{0} \bar{\rho}(\mathrm{r}, \mathrm{a})\left(\int_{0}^{\infty} \int_{0} \bar{\rho}\left(\mathrm{r}^{\prime}, \mathrm{a}^{\prime}\right) \phi\left(\mathrm{r}, \mathrm{a}, \mathrm{r}^{\prime}, \mathrm{a}^{\prime}\right) \mathrm{dr^{ \prime }} \mathrm{da}^{\prime}\right) \mathrm{drda}<1
$$

Let

then

$$
\rho_{1}(\mathrm{r}, \mathrm{a})=1-\int_{0}^{\infty} \int_{0} \bar{\rho}\left(\mathrm{r}^{\prime}, \mathrm{a}^{\prime}\right) \phi\left(\mathrm{r}, \mathrm{a}, \mathrm{r}^{\prime}, \mathrm{a}^{\prime}\right) \mathrm{dr} \mathbf{r}^{\prime} \mathrm{da}
$$

$$
\rho\left(\mathrm{r}, \mathrm{a}, \mathbf{r}^{\prime}, \mathrm{a}^{\prime}\right)=\bar{\rho}\left(\mathrm{r}^{\prime}, \mathrm{a}^{\prime}\right)\left[\frac{\rho_{1}(\mathrm{r}, \mathrm{a}) \rho_{1}\left(\mathbf{r}^{\prime}, \mathrm{a}^{\prime}\right)}{\int_{0}^{\infty} \int_{0}^{\infty} \bar{\rho}\left(\mathbf{r}^{\prime}, \mathrm{a}^{\prime}\right) \rho_{1}\left(\mathbf{r}^{\prime}, \mathrm{a}^{\prime}\right) \mathrm{d} \mathbf{r}^{\prime} \mathrm{da} \mathrm{a}^{\prime}}+\phi\left(\mathrm{r}, \mathrm{a}, \mathbf{r}^{\prime}, \mathrm{a}^{\prime}\right)\right]
$$

is a mixing function. Conversely, for every mixing function $\rho$ there exists a $\phi$ that satisfies the hypotheses of the theorem such that $\rho$ is given by (15) with $\rho_{1}$ defined by (14).

Proof: Let $\phi$ satisfy the hypotheses of the theorem and define $\rho_{1}$ via (14). From (14) we get

$$
\int_{0}^{\infty} \int_{0} \bar{\rho}\left(\mathrm{r}^{\prime}, \mathrm{a}^{\prime}\right) \rho_{1}(\mathrm{r}, \mathrm{a}) \mathrm{drd} \mathbf{a}=1-\int_{0}^{\infty} \int_{0} \bar{\rho}(\mathrm{r}, \mathrm{a}) \int_{0}^{\infty} \int_{0} \bar{\rho}\left(\mathrm{r}^{\prime}, \mathrm{a}^{\prime}\right) \phi\left(\mathrm{r}, \mathrm{a}, \mathbf{r}^{\prime}, \mathrm{a}^{\prime}\right) \mathrm{dr} \mathrm{r}^{\prime} \mathrm{da} \mathbf{a}^{\prime}>0,
$$

and $\rho$ as given by (15) is well defined. The assumptions on $\phi$ and Equation (13) imply that $\rho_{1}(\mathrm{r}, \mathrm{a})>0$ and thus that the mixing function $\rho$ as given by $(15)$ is $\geq 0$. Further, $\rho\left(\mathrm{r}, \mathrm{a}, \mathrm{r}^{\prime}, \mathrm{a}^{\prime}\right)=0$ whenever $\bar{\rho}\left(\mathrm{r}^{\prime}, \mathrm{a}^{\prime}\right)=0$, therefore $\rho\left(\mathrm{r}, \mathrm{a}, \mathrm{r}^{\prime}, \mathrm{a}^{\prime}\right) / \bar{\rho}\left(\mathrm{r}^{\prime}, \mathrm{a}^{\prime}\right)$ is well defined on the support of $\bar{\rho}$ and is jointly 
symmetric. Thus $\rho$ satisfies conditions (iii) and (iv). Finally, from (14) and (15) $\rho$ satisfies condition (ii), and hence, it is a mixing function.

In order to prove the converse, we first note that condition (iv) implies that $\rho\left(\mathrm{r}, \mathrm{a}, \mathrm{r}^{\prime}, \mathrm{a}^{\prime}\right) / \bar{\rho}\left(\mathrm{r}^{\prime}, \mathrm{a}^{\prime}\right)$ is well defined and non-negative. Hence, conditions (i) and (ii) guarantee the existence of an $\epsilon(r, a)>0$ and a subset $Q$ of $\mathscr{B}_{+}^{4}$ of positive measure such that $\rho / \bar{\rho}>\epsilon(\mathrm{r}, \mathrm{a})$ on $\mathrm{Q}$. Further, since $\rho\left(\mathrm{r}, \mathrm{a}, \mathrm{r}^{\prime}, \mathrm{a}^{\prime}\right) / \bar{\rho}\left(\mathrm{r}^{\prime}, \mathrm{a}^{\prime}\right)=\rho\left(\mathrm{r}^{\prime}, \mathrm{a}^{\prime}, \mathrm{r}, \mathrm{a}\right) / \bar{\rho}(\mathrm{r}, \mathrm{a})$ in $\mathcal{A}$ by (iii-iv), then $\rho\left(\mathrm{r}^{\prime}, \mathrm{a}^{\prime}, \mathrm{r}, \mathrm{a}\right) / \bar{\rho}(\mathrm{r}, \mathrm{a})>\epsilon(\mathrm{r}, \mathrm{a})$ in subset $\mathrm{Q}$.

Hence the set $Q$ is symmetric in $(r, a)$ and $\left(r^{\prime}, a^{\prime}\right)$. We now let

$$
\tilde{Q}=\left\{(r, a,):\left(r, a, r^{\prime}, a^{\prime}\right) \in Q \text { for some }\left(\mathbf{r}^{\prime}, a^{\prime}\right) \in \mathscr{B}_{+}^{2}\right\}
$$

and let $\chi_{\tilde{Q}}$ denote the characteristic function of this set. Define

$$
\begin{aligned}
& \rho_{1}(\mathrm{r}, \mathrm{a})=\epsilon \chi_{\left.\tilde{Q}^{(}, \mathrm{a}\right)} \int_{0}^{\infty} \int \chi_{\tilde{Q}^{(u, v)} \bar{\rho}(\mathrm{u}, \mathrm{v}) \mathrm{dud},}
\end{aligned}
$$

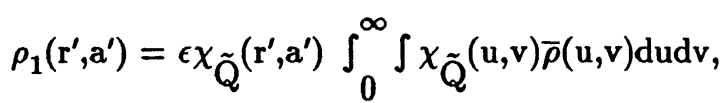

where $\epsilon$, based on the above discussion, can be chosen independently of $(r, a)$ and $\left(r^{\prime}, a^{\prime}\right)$. Then $\rho_{1} \geq 0$ is measurable and

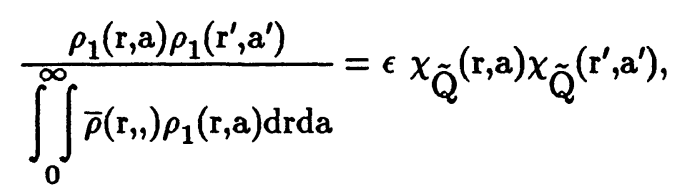

which is symmetric in $(r, a)$ and $\left(r^{\prime}, a^{\prime}\right)$. If we now let

$$
\phi\left(\mathrm{r}, \mathrm{a}, \mathbf{r}^{\prime}, \mathrm{a}^{\prime}\right) \equiv \frac{\rho\left(\mathrm{r}, \mathrm{a}, \mathbf{r}^{\prime}, \mathrm{a}^{\prime}\right)}{\bar{\rho}\left(\mathbf{r}^{\prime}, \mathrm{a}^{\prime}\right)} \frac{\rho_{1}(\mathrm{r}, \mathrm{a}) \rho_{1}\left(\mathrm{r}^{\prime}, \mathrm{a}^{\prime}\right)}{\int_{0}^{\infty} \int_{0} \bar{\rho}(\mathrm{r}, \mathrm{a}) \rho_{1}(\mathrm{r}, \mathrm{a}) \mathrm{drda}} \frac{\rho\left(\mathrm{r}, \mathrm{a}, \mathrm{r}^{\prime}, \mathrm{a}^{\prime}\right)}{\bar{\rho}\left(\mathbf{r}^{\prime}, \mathrm{a}^{\prime}\right)}-\frac{\rho_{1}(\mathrm{r}, \mathrm{a}) \rho_{1}\left(\mathrm{r}^{\prime}, \mathrm{a}^{\prime}\right)}{\int_{0}^{\infty} \int \bar{\rho}(\mathrm{r}, \mathrm{a}) \rho_{1}(\mathrm{r}, \mathrm{a}) \mathrm{drda}}
$$

then $\phi$ is symmetric in $(r, a)$ and $\left(r^{\prime}, a^{\prime}\right)$; that is, $\phi\left(r, a, r^{\prime}, a^{\prime}\right)=\phi\left(r^{\prime}, a^{\prime}, r, a\right)$, and (14) holds. Finally, from (14) we get

$$
\int_{0}^{\infty} \int_{\rho} \bar{\rho}(\mathrm{r}, \mathrm{a})\left(\int_{0}^{\infty} \int_{0} \bar{\rho}\left(\mathrm{r}^{\prime}, \mathrm{a}^{\prime}\right) \phi\left(\mathrm{r}, \mathrm{a}, \mathrm{r}^{\prime}, \mathrm{a}^{\prime}\right) \mathrm{dr} \mathrm{r}^{\prime} \mathrm{da} \mathbf{a}^{\prime}\right) \mathrm{drda}=1-\int_{0}^{\infty} \int_{0} \bar{\rho}(\mathrm{r}, \mathrm{a}) \rho_{1}(\mathrm{r}, \mathrm{a}) \mathrm{drda}<1,
$$

and the proof is complete.

One especially interesting class of mixing functions comes from the choice $\phi\left(r, a, r^{\prime}, a^{\prime}\right)=\alpha \phi\left(r-a, r^{\prime}-a^{\prime}\right)$, where $\phi$ is even in both variables jointly, $\alpha>0$, and 


$$
\int_{0}^{\infty} \int_{0} \bar{\rho}\left(\mathbf{r}^{\prime}, \mathrm{a}^{\prime}\right) \phi\left(\mathrm{r}-\mathbf{r}^{\prime}, \mathbf{a}-\mathrm{a}^{\prime}\right) \mathrm{dr} \mathbf{r}^{\prime} \mathrm{da} \mathbf{a}^{\prime}<\infty
$$

Then (15) yields a mixing function provided

where

$$
\begin{array}{r}
0<(1-\alpha \bar{\rho} * \phi(\mathrm{r}, \mathrm{a}))\left(1-\alpha \bar{\rho} * \phi\left(\mathrm{r}^{\prime}, \mathrm{a}^{\prime}\right)\right) \\
\alpha \phi\left(\mathrm{r}-\mathrm{r}^{\prime}, \mathrm{a}-\mathrm{a}^{\prime}\right)\left(1-\alpha \iiint_{0}^{\infty} \int \bar{\rho}(\mathrm{r}, \mathrm{a},) \bar{\rho}\left(\mathrm{r}^{\prime}, \mathrm{a}^{\prime}\right) \phi\left(\mathrm{r}-\mathrm{r}^{\prime}, \mathrm{a}^{-} \mathbf{a}^{\prime}\right) \mathrm{drdadr} \mathbf{r}^{\prime} \mathrm{a}^{\prime},\right.
\end{array}
$$

$$
\bar{\rho} * \phi(\mathbf{r}, \mathrm{a})=\int_{0}^{\infty} \int_{0} \bar{\rho}\left(\mathbf{r}^{\prime}, \mathrm{a}^{\prime}\right) \phi\left(\mathbf{r}-\mathbf{r}^{\prime}, \mathbf{a}-\mathbf{a}^{\prime}\right) \mathrm{dr} \mathbf{r}^{\prime} \mathbf{d a}
$$

This condition is satisfied whenever

$$
1-\alpha \bar{\rho} * \phi(\mathrm{r}, \mathrm{a})>0
$$

since $\alpha \phi \geq 0$ and (17) implies that the last term in (16) is positive. These observations yield the following corollary which is the age-structured version of neighborhood mixing function of BCC.

Corollary 4.5: Let $\phi \geq 0, \phi: \mathscr{B}^{2} \rightarrow \mathscr{P}^{+}$be jointly even: $\phi(r, a)=\phi(-r,-a)$, and suppose that for some $\alpha>0$,

$$
\alpha \int_{0}^{\infty} \int_{\rho} \bar{\rho}\left(\mathrm{r}^{\prime}, \mathrm{a}^{\prime}\right) \phi\left(\mathrm{r}-\mathrm{r}^{\prime}, \mathrm{a}-\mathrm{a}^{\prime}\right) \mathrm{dr^{ \prime }} \mathrm{da}^{\prime}<1, \quad \text { for } \mathrm{r}, \mathrm{a} \in[0, \infty)
$$

Then

$$
\rho\left(\mathrm{r}, \mathrm{a}, \mathbf{r}^{\prime}, \mathrm{a}^{\prime}\right)=\bar{\rho}\left(\mathbf{r}^{\prime}, \mathrm{a}^{\prime}\right)\left[\frac{\rho_{1}(\mathrm{r}, \mathrm{a}) \rho_{1}\left(\mathbf{r}^{\prime}, \mathrm{a}^{\prime}\right)}{\iint_{0}^{\infty} \bar{\rho}(\mathrm{r}, \mathrm{a}) \rho_{1}(\mathrm{r}, \mathrm{a}) \mathrm{drda}}+\alpha \phi\left(\mathbf{r}-\mathbf{r}^{\prime}, \mathbf{a}-\mathbf{a}^{\prime}\right)\right]
$$

is a mixing function, where

$$
\rho_{1}(\mathrm{r}, \mathrm{a})=1-\alpha \int_{0}^{\infty} \int_{0} \bar{\rho}\left(\mathrm{r}^{\prime}, \mathrm{a}^{\prime}\right) \phi\left(\mathbf{r}-\mathrm{r}^{\prime}, \mathrm{a}-\mathrm{a}^{\prime}\right) \mathrm{dr} \mathbf{r}^{\prime} \mathrm{da}
$$

Theorems 4.3 and 4.4 and Corollary 4.5 can be used to construct mixing functions of varying degrees of complexity. We shall give examples of such functions in the next section.

Theorem 4.1 gave a mathematical characterization of the total proportionate mixing function appearing in case III of Table I. There are similar characterizations of the other cases in that table. For example, the mixing function in case II, proportionate activity mixing has the form

$$
\rho\left(\mathrm{r}, \mathrm{a}, \mathrm{r}^{\prime}, \mathrm{a}^{\prime}\right)=\tilde{\rho}\left(\mathrm{r}, \mathrm{a}, \mathrm{a}^{\prime}\right) \bar{\rho}\left(\mathbf{r}^{\prime}, \mathrm{a}^{\prime}\right)
$$


and $\tilde{\rho}$ is independent of the variable $\mathbf{r}^{\prime}$. Conversely, if we assume that

$$
\rho\left(\mathrm{r}, \mathrm{a}, \mathbf{r}^{\prime}, \mathrm{a}^{\prime}\right)=\rho_{1}\left(\mathrm{r}, \mathrm{a}, \mathrm{a}^{\prime}\right) \rho_{2}\left(\mathbf{r}^{\prime}, \mathrm{a}^{\prime}\right),
$$

then from (9) we obtain

$$
\mathrm{f}(\mathrm{r}, \mathrm{a})=\rho_{2}(\mathrm{r}, \mathrm{a}) \int_{0}^{\infty} \int_{1}^{\infty} \rho_{1}\left(\mathrm{r}^{\prime}, \mathrm{a}^{\prime}, \mathrm{a}\right) \mathrm{f}\left(\mathrm{r}^{\prime}, \mathrm{a}^{\prime}\right) \mathrm{dr} \mathrm{r}^{\prime} \mathrm{da} \mathbf{a}^{\prime}=\rho_{2}(\mathrm{r}, \mathrm{a}) \mathrm{g}(\mathrm{a}) .
$$

Using this in (22) we get

$$
\rho\left(\mathrm{r}, \mathrm{a}, \mathrm{r}^{\prime}, \mathrm{a}^{\prime}\right)=\frac{\rho_{1}\left(\mathrm{r}, \mathrm{a}, \mathrm{a}^{\prime}\right)}{\mathrm{g}(\mathrm{a})} \mathrm{f}(\mathrm{r}, \mathrm{a})
$$

which implies that $\rho$ is of the form given by (21) where

$$
\tilde{\rho}\left(\mathrm{r}, \mathrm{a}, \mathrm{a}^{\prime}\right)=\frac{\rho_{1}\left(\mathrm{r}, \mathrm{a}, \mathrm{a}^{\prime}\right)}{\mathrm{g}(\mathrm{a})} \int_{0}^{\infty} \int_{0} \mathrm{f}(\mathrm{u}, \mathrm{v}) \mathrm{dud} \mathbf{v} .
$$

Thus the proportionate activity mixing term (21) is the unique mixing term with the separability property given in (22). Here uniqueness is modulo regrouping of terms in the product in (22) and the cancellation of common factors. Similar characterizations hold for the other cases given in Tables Ia Ib.

The results in this section can be specialized to the case where there is no age structure in the population. In this simpler setting they yield new results concerning the mixing function $\rho\left(\mathrm{r}, \mathrm{r}^{\prime}\right)$ studied by BCC. We give here two of these results that allow for the easier construction of mixing functions in this simpler setting following from assuming no age-dependence in Theorems 4.3 and 4.4.

Corollary 4.6: $\rho\left(r, r^{\prime}\right)$ is a mixing function, if and only if there exists a symmetric function $\phi\left(r, r^{\prime}\right) \geq 0$ such that

$$
\int_{0}^{\infty} \bar{\rho}\left(\mathbf{r}^{\prime}\right) \phi\left(r, r^{\prime}\right) d r^{\prime}=1
$$

and

$$
\rho\left(\mathbf{r}, \mathbf{r}^{\prime}\right)=\bar{\rho}\left(\mathbf{r}^{\prime}\right) \phi\left(\mathbf{r}, \mathbf{r}^{\prime}\right)
$$

Corollary 4.7: Let $\phi: \mathscr{B}_{+}^{2} \rightarrow \Re^{+}$be measurable and symmetric, and suppose that

$$
\int_{0}^{\infty} \bar{\rho}\left(\mathbf{r}^{\prime}\right) \phi\left(\mathbf{r}, \mathbf{r}^{\prime}\right) \mathrm{d} \mathbf{r}^{\prime} \leq 1, \text { and } \int_{0}^{\infty} \bar{\rho}\left(\mathbf{r}^{\prime}\right) \int_{0}^{\infty} \bar{\rho}\left(\mathbf{r}^{\prime}\right) \phi\left(\mathbf{r}, \mathbf{r}^{\prime}\right) \mathrm{d} \mathbf{r}^{\prime} \mathrm{dr} \leq 1 \text {. }
$$

Letting

$$
\rho_{1}(\mathrm{r})=1-\int_{0}^{\infty} \bar{\rho}\left(\mathrm{r}^{\prime}\right) \phi\left(\mathrm{r}, \mathrm{r}^{\prime}\right) \mathrm{dr}
$$


then

$$
\rho\left(\mathbf{r}, \mathbf{r}^{\prime}\right)=\bar{\rho}(\mathbf{r})\left[\frac{\rho_{1}(\mathbf{r}) \rho_{1}\left(\mathbf{r}^{\prime}\right)}{\int_{0}^{\infty} \bar{\rho}(\mathrm{r}) \rho_{1}(\mathrm{r}) \mathrm{dr}}+\phi\left(\mathbf{r}, \mathbf{r}^{\prime}\right)\right]
$$

is a mixing function. Conversely, for every mixing function $\rho$ there exists $\phi$ satisfying the above hypothesis such that $\rho$ is given by (25), with $\rho_{1}$ defined by (24).

5. Age- and risk-based model with variable infectivity: disease transmission in a single population.

We now use some of the above observations to formulate the simplest single population model of the $\mathrm{S} \rightarrow \mathrm{I}$ type where there is no recovery from the disease. Since one of our main goals is to model the transmission of HIV, we begin with the more general model as dictated by the transfer diagram $\mathrm{S} \rightarrow \mathrm{I} \rightarrow \mathrm{A}$, with A denoting those individuals with severe symptoms or with "full-blown" AIDS. In this section, we deal with a dynamic model of the transmission of HIV/AIDS in a single, sexually-active homosexual male population. More general models, especially two-sex models, will be treated in the near future (see Section 6). We base our model on the following assumptions:

- There is a possibly varying recruitment rate $\Lambda$ into the population.

- The population does not reproduce itself via birth.

- The population internal variables are:

$$
\begin{aligned}
& \mathbf{a}=\text { chronological age, } \tau=\text { infection age (for the I and A groups), } \\
& \mathbf{r}=\text { activity level. }
\end{aligned}
$$

With these assumptions we obtain the following set of equations for $S(r, a, t), I(r, a, \tau, t)$, and $A(r, a, \tau, t)$ describing the disease dynamics:

$$
\begin{aligned}
& \frac{\partial \mathrm{S}}{\partial \mathrm{t}}+\frac{\partial \mathrm{S}}{\partial \mathrm{a}}+\mu(\mathrm{a}) \mathrm{S}=\Lambda(\mathrm{r}, \mathrm{a}, \mathrm{t}, \mathrm{T}(\mathrm{a}, \mathrm{r}, \mathrm{t}))-\mathrm{B}(\mathrm{r}, \mathrm{a}, \mathrm{t}) \\
& \frac{\partial \mathrm{I}}{\partial \mathrm{t}}+\frac{\partial \mathrm{I}}{\partial \mathrm{a}}+\frac{\partial \mathrm{I}}{\partial \tau}+\{\mu(\mathrm{a})+\xi(\mathrm{a}, \tau)+\gamma(\mathrm{a}, \tau)\} \mathrm{I}=0 \\
& \frac{\partial \mathrm{A}}{\partial \mathrm{t}}+\frac{\partial \mathrm{A}}{\partial \mathrm{a}}+\frac{\partial \mathrm{A}}{\partial \tau}+\{\mu(\mathrm{a})+\eta(\mathrm{a}, \tau)\} \mathrm{A}=\gamma(\mathrm{a}, \tau) \mathrm{I}
\end{aligned}
$$

where

$$
\mathrm{S}(\mathrm{r}, 0, \mathrm{t})=\mathrm{I}(\mathrm{r}, 0, \tau, \mathrm{t})=\mathrm{A}(\mathrm{r}, 0, \tau, \mathrm{t})=0, \mathrm{I}(\mathrm{r}, \mathrm{a}, 0, \mathrm{t})=\mathrm{B}(\mathrm{r}, \mathrm{a}, \mathrm{t}) .
$$

$\xi$ and $\eta$ denote the disease-induced mortalities, and $\gamma$ is the rate of entry into the AIDS class. The 
other parameters are as previously defined, and $(t, a, \tau) \in \stackrel{\Re^{3}}{\text {. }}$.

For this model, we have obtained a general expression which characterizes the basic reproductive number $R_{0}$ of the disease. The basic reproductive number is defined as the number of secondary infections generated by a "typical" infectious individual in a population of susceptibles (for a recent discussion see Diekmann et al. 1989). The basic reproductive number determines whether or not a disease can invade, and is therefore of utmost epidemiological importance. For arbitrary mixing functions, we cannot determine an explicit expression for $\mathrm{R}_{0}$ and, therefore we provide only an implicit expression as described in the following discussion.

If $I \equiv A \equiv 0$, then we obtain the disease-free state $(S, 0,0)$, where $S$ satisfies:

$$
\frac{\partial \mathrm{S}}{\partial \mathrm{t}}+\frac{\partial \mathrm{S}}{\partial \mathrm{a}}+\mu(\mathrm{a}) \mathrm{S}=\Lambda(\mathrm{r}, \mathrm{a}, \mathrm{t})
$$

If $\Lambda$ is time independent, $\Lambda(r, a, t)=\Lambda(r, a)$, and we obtain the steady-state disease-free solution $\tilde{\mathrm{S}}$ which satisfies

$$
\frac{\mathrm{d} \tilde{\mathrm{S}}}{\mathrm{dt}}+\mu(\mathrm{a}) \tilde{\mathrm{S}}=\Lambda(\mathrm{r}, \mathrm{a})
$$

and consequently,

$$
\tilde{S}(r, a)=\int_{0}^{a} e^{-\int_{x}^{a} \mu(y) d y} \Lambda(r, x) d x .
$$

We want to investigate the stability of $\tilde{S}$ and how it is affected by the choice of mixing function $\rho$. For simplicity we assume that $\mathrm{C}$ is not dependent on the population size; however, much of the analysis that follows extends directly to the case where $\mathrm{C}$ does depend on the population size. We note that Equation (28) is decoupled from the first two, so we need only to study the system for $\mathrm{S}$ and I (Equations 26-27). At an endemic equilibrium $\left(S^{*}(r, a), I^{*}(r, a, \tau)\right)$, the incidence rate is given by $B^{*}(r, a)=k^{*}\left(r, a, \rho^{*}\right) C(r, a) S^{*}(r, a)$, where $\rho^{*}$ denotes the mixing at equilibrium (i.e., evaluated at $\left.\left(S^{*}, I^{*}\right)\right)$ and

$$
\mathrm{k}^{*}\left(\mathrm{r}, \mathrm{a}, \rho^{*}\right)=\int_{0}^{\infty} \int\left[\int_{0}^{\mathbf{a}^{\prime}} \beta\left(\mathrm{r}, \mathrm{a}, \tau, \mathrm{r}^{\prime}, \mathrm{a}^{\prime}\right) \mathcal{F}\left(\mathrm{k}^{*}, \mathrm{r}, \mathrm{a}, \mathrm{r}^{\prime}, \mathrm{a}^{\prime}\right) \mathrm{d} \tau\right] \mathrm{dr} \mathrm{r}^{\prime} \mathrm{da}^{\prime}
$$

where $\mathscr{F} \equiv \mathscr{F}\left(\mathrm{k}^{*}, \mathrm{r}, \mathrm{a}, \mathbf{r}^{\prime}, \mathrm{a}^{\prime}\right)$ denotes a nonlinear functional which depends on the particular mixing function $\rho^{*}$. Specifically, we have that 


$$
\mathscr{F}\left(k^{*}, r, a, r^{\prime}, a^{\prime}\right)=\frac{\rho^{*}\left(r, a, r^{\prime}, a^{\prime}\right) I^{*}\left(r^{\prime}, a^{\prime}, \tau\right)}{S^{*}\left(r^{\prime}, a^{\prime}\right)+\int_{0}^{\infty} I^{*}\left(r^{\prime}, a^{\prime}, \tau\right) d \tau} .
$$

The equations for $S^{*}(r, a)$ and $I^{*}(r, a, \tau)$ are:

$$
\begin{gathered}
\frac{\mathrm{dS}^{*}}{\mathrm{dt}}+\mu(\mathrm{a}) \mathrm{S}^{*}=\Lambda(\mathrm{r}, \mathrm{a})-\mathrm{k}^{*}\left(\mathrm{r}, \mathrm{a}, \rho^{*}\right) \mathrm{C}(\mathrm{r}, \mathrm{a}) \mathrm{S}^{*} \\
\frac{\partial \mathrm{I}^{*}}{\partial \mathrm{a}}+\frac{\partial \mathrm{I}^{*}}{\partial \tau}+\{\mu(\mathrm{a})+\epsilon(\mathrm{a}, \tau)+\gamma(\mathrm{a}, \tau)\} \mathrm{I}^{*}=0 \\
\mathrm{I}^{*}(\mathrm{r}, \mathrm{a}, 0)=\mathrm{k}^{*}\left(\mathrm{r}, \mathrm{a}, \rho^{*}\right) \mathrm{C}(\mathrm{r}, \mathrm{a}) \mathrm{S}^{*}(\mathrm{r}, \mathrm{a}) .
\end{gathered}
$$

Equation (35) has the solution

$$
S^{*}(r, a)=\int_{0}^{a} e^{-\int_{x}^{a}\left[\mu(y)+k^{*}\left(r, y, \rho^{*}\right) C(r, y)\right] d y} \Lambda(r, x) d x,
$$

which can now be substituted in Equation (36) to yield a simple linear first order partial differential equation for $\mathrm{I}^{*}$ which can be integrated along characteristics to yield:

$\mathrm{I}^{*}(\mathrm{r}, \mathrm{a}, \tau)=\left[\begin{array}{cc}0, & \text { if } \mathrm{a}<\tau \\ \mathrm{k}^{*}\left(\mathrm{r}, \mathrm{a}-\tau, \rho^{*}\right) \mathrm{C}(\mathrm{r}, \mathrm{a}-\tau) \mathrm{S}^{*}(\mathrm{r}, \mathrm{a}-\tau) \mathrm{e} & -\int_{0}^{\tau}[\mu(\mathrm{a}+\sigma-\tau)+\epsilon(\mathrm{a}+\sigma-\tau, \sigma)+\gamma(\mathrm{a}+\sigma-\tau, \sigma] \mathrm{d} \sigma\end{array}\right.$

where $S^{*}(r, a)$ is given by (38). We now substitute the expressions for $S^{*}$ and $I^{*}$ in (33), and note that the form of the nonlinear functional $\mathscr{F}$ depends on the particular mixing function $\rho^{*}$ used in (33), but that it always has the property that

$$
\mathscr{F}\left(0, \mathrm{r}, \mathrm{a}, \mathbf{r}^{\prime}, \mathrm{a}^{\prime}\right)=0 .
$$

Equation (33) determines the threshold for the existence of an endemic equilibrium solution. First $\mathrm{k}\left(\mathrm{r}, \mathrm{a}, \rho^{*}\right) \equiv 0$ is always a solution of $(33)$ and this corresponds to the disease-free state. Any other non-negative solution of (33) corresponds to an endemic equilibrium. To gain further understanding of the role of the mixing function in the determination of endemic equilibria it may be of value to study Equation (33) for very specific mixing functions. This is particularly relevant as the recent results of Huang (1989), Huang et al. (1990) and Castillo-Chavez et al. (1989d, e) have shown that the existence of multiple endemic equilibria may be due to the combined effects of va iable population size and 
non-symmetric mixing functions. In the following subsection we compute the threshold for the total proportionate mixing case.

\subsection{Threshold for the total proportionate mixing case}

In the total proportionate mixing case we have

$$
\rho\left(\mathrm{r}, \mathrm{a}, \mathbf{r}^{\prime}, \mathrm{a}^{\prime}, \mathrm{t}\right)=\bar{\rho}\left(\mathrm{r}^{\prime}, \mathrm{a}^{\prime}, \mathrm{t}\right)=\frac{\mathrm{C}\left(\mathrm{r}^{\prime}, \mathrm{a}^{\prime}\right) \mathrm{T}\left(\mathrm{r}^{\prime}, \mathrm{a}^{\prime}, \mathrm{t}\right)}{\iint_{0}^{\infty} \mathrm{C}(\mathrm{u}, \mathrm{v}) \mathrm{T}(\mathrm{u}, \mathrm{v}, \mathrm{t}) \mathrm{dudv}},
$$

which, when substituted in (33) and upon using (38) yields

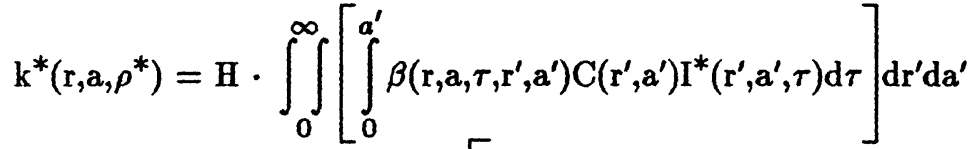

$$
\begin{aligned}
& =\mathrm{H} \cdot \int_{0}^{\infty} \int_{0} \mathrm{C}\left(\mathrm{r}^{\prime}, \mathrm{a}^{\prime}\right)\left[\int _ { 0 } ^ { a ^ { \prime } } \left\{\beta\left(\mathrm{r}, \mathrm{a}, \tau, \mathrm{r}^{\prime}, \mathrm{a}^{\prime}\right) \mathrm{k}^{*}\left(\mathbf{r}^{\prime}, \mathrm{a}^{\prime}-\tau, \rho^{*}\right) \mathrm{C}\left(\mathbf{r}^{\prime}, \mathrm{a}^{\prime}-\tau\right)\right.\right. \\
& \cdot \mathrm{e}^{-\int_{0}^{\tau}\left[\mu\left(\mathrm{a}^{\prime}+\sigma-\tau\right)+\epsilon\left(\mathrm{a}^{\prime}+\sigma-\tau, \sigma\right)+\gamma\left(\mathrm{a}^{\prime}+\sigma-\tau, \sigma\right)\right] \mathrm{d} \sigma} \\
& \left.\left.\int_{0}^{a^{\prime}-\tau-\int_{x}^{a^{\prime}-\tau} \cdot\left[\mu(y)+k^{*}\left(r^{\prime}, y, \rho^{*}\right) C\left(r^{\prime}, y\right)\right] d y} \Lambda\left(r^{\prime}, x\right) d x\right\} d \tau\right] d r^{\prime} \mathrm{da}^{\prime}
\end{aligned}
$$

where

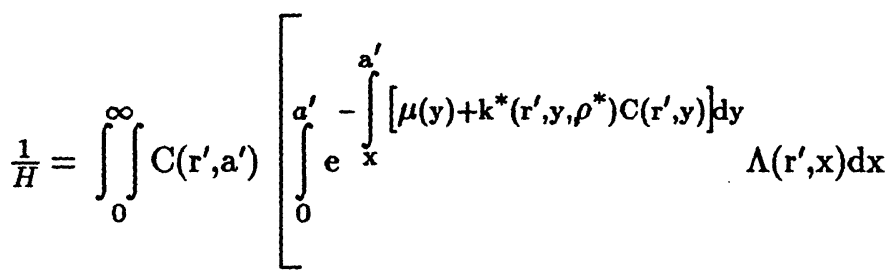

$$
\begin{aligned}
& +\int_{0}^{\infty}\left\{k^{*}\left(\mathrm{r}^{\prime}, \mathrm{a}^{\prime}-\tau, \rho^{*}\right) \mathrm{C}\left(\mathrm{r}^{\prime}, \mathrm{a}^{\prime}-\tau\right) \int_{0}^{a^{\prime}-\tau-\int_{\mathrm{a}}^{\mathrm{a}^{\prime}-\tau}\left[\mu(\mathrm{y})+\mathrm{k}^{*}\left(\mathrm{r}^{\prime}, \mathrm{y}, \rho^{*}\right) \mathrm{C}\left(\mathrm{r}^{\prime}, \mathrm{y}\right)\right] \mathrm{dy}} \Lambda\left(\mathrm{r}^{\prime}, \mathrm{x}\right) \mathrm{dx}\right. \\
& \left.\left.\mathrm{e}^{-\int_{0}^{\tau}\left[\mu\left(\mathrm{a}^{\prime}+\sigma-\tau\right)+\epsilon\left(\mathrm{a}^{\prime}+\sigma-\tau, \sigma\right)+\gamma\left(\mathrm{a}^{\prime}+\sigma-\tau, \sigma\right)\right] \mathrm{d} \sigma}\right\}_{\mathrm{d} \tau}\right] \mathrm{dr}^{\prime} \mathrm{da}^{\prime}
\end{aligned}
$$


The expression on the right-hand side of (41) is fairly complicated; however, it is still possible to derive explicit conclusions from it. Clearly, $\mathrm{k} \equiv 0$ is a solution of $(41)-(42)$, and yields the diseasefree equilibrium. One case that can be completely analyzed is when

$$
\beta\left(\mathrm{r}, \mathrm{a}, \tau, \mathrm{r}^{\prime}, \mathrm{a}^{\prime}\right)=\beta\left(\tau, \mathbf{r}^{\prime}, \mathrm{a}^{\prime}\right),
$$

that is, the probability of acquiring the disease, given that contact has occurred, does not depend on the age or activity level of the susceptible. In this case, $\mathrm{k}^{*}$ is independent of $\mathrm{r}$ and $\mathrm{a}$ and can be factored out of the integrals to reduce (41) to

$$
\begin{aligned}
& 1=\mathrm{H} \cdot \int_{0}^{\infty} \int_{0} \mathrm{C}\left(\mathrm{r}^{\prime}, \mathrm{a}^{\prime}\right) \int_{0}^{a^{\prime}}\left\{\int_{0}^{a^{\prime}-\tau-\mathrm{k}^{*} \int_{x}^{\mathrm{a}^{\prime} \tau} \mathrm{e}\left(\mathrm{r}^{\prime} \mathrm{y}\right) \mathrm{dy}-\int_{x}^{\mathrm{a}^{\prime}-\tau} \mu(\mathrm{y}) \mathrm{dy}} \Lambda\left(\mathrm{r}^{\prime}, \mathrm{x}\right) \mathrm{dx}\right. \\
&\left.\left.\cdot \beta\left(\tau, \mathrm{r}^{\prime}, \mathrm{a}^{\prime}\right) \mathrm{C}\left(\mathrm{r}^{\prime}, \mathrm{a}^{\prime}-\tau\right) \mathrm{e}^{-\int_{0}^{\tau}\left[\mu\left(\mathrm{a}^{\prime}+\sigma-\tau\right)+\epsilon\left(\mathrm{a}^{\prime}+\sigma-\tau, \sigma\right)+\gamma\left(\mathrm{a}^{\prime}+\sigma-\tau, \sigma\right)\right] \mathrm{d} \sigma}\right\} \mathrm{d} \tau\right] \mathrm{dr} \mathrm{da}^{\prime} \\
& \equiv \mathrm{R}\left(\mathrm{k}^{*}\right)
\end{aligned}
$$

From (43) it follows that if $R(0)=R_{0}>1$, where

$$
\left.\mathrm{R}_{0}=\left[\frac{1}{\iint_{0}^{\infty} \mathrm{C}\left(\mathrm{r}^{\prime}, \mathrm{a}^{\prime}\right)\left[\int_{0}^{a^{\prime}} \mathrm{e}^{\mathrm{a}^{\prime}} \mu(\mathrm{y}) \mathrm{dy}\right.} \Lambda\left(\mathrm{r}^{\prime}, \mathrm{x}\right) \mathrm{dx}\right] \mathrm{dr^{ \prime } \mathrm { da } \mathrm { a } ^ { \prime }}\right]
$$$$
\cdot \int_{0}^{\infty} \int_{0} \mathrm{C}\left(\mathrm{r}^{\prime}, \mathrm{a}^{\prime}\right)\left[\int _ { 0 } ^ { a ^ { \prime } } \left\{\int _ { 0 } ^ { a ^ { \prime } - \tau - \int _ { x } ^ { \mathrm { a } ^ { \prime } } \mu ( \mathrm { y } ) \mathrm { dy } } \Lambda \left(\mathrm{r}^{\prime}, \mathrm{x}(\mathrm{dx}) \cdot \beta\left(\tau, \mathrm{r}^{\prime}, \mathrm{a}^{\prime}\right) \mathrm{C}\left(\mathrm{r}^{\prime}, \mathrm{a}^{\prime}-\tau\right)\right.\right.\right.
$$

$$
\left.\left.\cdot \int_{0}^{-\int_{0}^{\tau}\left[\mu\left(\mathrm{a}^{\prime}+\sigma-\tau\right)+\epsilon\left(\mathrm{a}^{\prime}+\sigma-\tau, \sigma\right)+\gamma\left(\mathrm{a}^{\prime}+\sigma-\tau, \sigma\right)\right] \mathrm{d} \sigma}\right\}_{\mathrm{d} \tau}\right] \mathrm{dr} \mathrm{rad}^{\prime}
$$


then there exists a $k>0$ satisfying (43) provided that $C(r, a)$ is not identically zero. Equation (44) provides an explicit expression for the endemic threshold or basic reproductive number $R_{0}$.

The basic reproductive number, allows us to study the effects of demographic and epidemiological parameters in disease transmission. For example, since $R_{0}$ is given by three types of risk- and age- dependent expressions: those involving death-adjusted "recruitment", those involving time spent in the infectious state - appropriately weighted by infectivity, and those involving average sexual activity, then any uniform increase in these expressions (i.e., any increase in the incubation period, in the mean number of sexual partners, or in the recruitment of susceptibles) will generate an increase in the reproductive number. However, a change in any of these parameters, which represents an average increase over old age and activity classes, need not lead to an increase in $R_{0}$, and in fact, may cause $R_{0}$ to decrease due to the close coupling between these epidemiological parameters and the age- and activity level-dependent demographic parameters. The results concerning uniform increases agree in principle with those found for reproductive numbers for age-independent homogeneously mixing models in which the reproductive number is given as the product of three factors: the mean infectious period, the mean number of sexual partners per unit time, and the average infectivity (see Anderson and May 1987, Busenberg and Castillo-Chavez 1989). Also note that the reproductive number, in models in which the mean number of sexual partners depends on the "recruitment" rate, is a nondecreasing function of this rate (see Busenberg et al. 1989, Castillo-Chavez et al. 1989b, c, d and Thieme and Castillo-Chavez 1989a, b), but the lack of an age- and activity-level structure makes it impossible to use these simpler age- and activity-independent models in the fine tuning and testing of specific control measures. The expression for $R_{0}$, given by Equation (44) lets us look at the effects of potential control measures that are targeted to individuals of specific age and activity levels.

\section{Conclusion}

In this paper we have extended the mixing framework of $\mathrm{BCC}$ through the incorporation of agestructure, and have found the general solution to the mixing problem for a sexually-active homosexual population. This general solution, as well as a number of other results, are new even in the simpler 
context where there is no age-dependence. We have clarified the role of proportionate mixing by showing that it is the only separable solution, and have formulated a general epidemic model for a single, age-dependent, sexually-active homosexual population with distributed activity levels. An explicit expression for the reproductive number for the special case of proportionate mixing has been determined.

Our results show that the reproductive number is a complex nonlinear function of the mixing. Future clarification of the role of the mixing function on the reproductive number may be accomplished by analyzing models with specific simple mixing functions (such as those specified in Section 3 or in BCC) and convex linear combinations of them. Some preliminary work in this direction has already began (see Nold 1980, Jacquez et al. 1988, BCC, and Busenberg and CastilloChavez 1989, Castillo-Chavez et al. 1989d, Gupta et al. 1989, Huang 1989, and Huang et al. 1990).

Andrea Pugliese' remarks that our mixing framework can be easily generalized to include geographical variability by assuming that each neighborhood has its own mixing function, $\rho^{j}\left(r, a, r^{\prime}, a^{\prime}\right)$, which now denotes the proportion of contacts between "typical" $(r, a)$ individuals at neighborhood $j$ with "typical" ( $\left.r^{\prime}, a^{\prime} g\right)$ individuals. Each of these "localized" mixing functions satisfies the mixing axioms and hence can be expressed through our representation theorem. In addition, the spatial movement of individuals has to be specified with a migration or movement matrix such as those found in the work of Sattenspiel (1987a, b) and Sattenspiel and Simon (1988). This general framework may be very useful in theoretical considerations; however, its applicability to specific situations is probably extremely limited due to the tremendous number of parameters involved.

Finally, the extension of the above framework to two-sex populations is straightforward. We have already determined the general solution to the corresponding two-sex framework. Our formulation of this two-sex framework (along the lines of the one-sex framework described in this article) provides an alternative formulation to the problem of pairing (see Dietz and Hadeler 1988). Models that consider pairs and follow the dynamics of pairs have been studied by Kendall (1949), Fredrickson (1971), Dietz and Hadeler (1988), Dietz (1988), Hadeler (1989a, b), and Waldstätter (1989). We have formulated analogous models that utilize solutions of our two-sex framework. Our 
approach (one- and two-sex formulations) has perhaps the added advantage that it allows direct comparison of the dynamics of disease in models that follow pairs and those that do not (i.e., the duration of each partnership is zero) through the use of equivalent pairing (mixing) functions. A manuscript discussing a model with pairs that incorporates this approach is under preparation (see Castillo-Chavez and Busenberg 1989).

\section{ACKNOWLEDGMENTS}

This research has been partially supported by the Center for Applied Mathematics at Cornell University and NSF grant DMS-8902712 to Stavros Busenberg, and NSF grant DMS-8906580, NIAID Grant R01 A129178-01, and Hatch project grant NYC 151-409, USDA to Carlos Castillo-Chavez. We thank Steve J. Schwager for his valuable comments. 
Table Ia

\begin{tabular}{|c|c|c|}
\hline $\begin{array}{l}\text { Type \& } \\
\text { Name }\end{array}$ & $\begin{array}{l}\text { Force of infection term }=B(r, a, t) \\
\frac{B(r, a, t)}{C(r, a)}\end{array}$ & $\begin{array}{c}\text { Proportion condition } \\
\text { (ii) } \int_{0}^{\infty} \int\left(\mathrm{r}, \mathrm{a}, \mathrm{r}^{\prime}, \mathrm{a}^{\prime}, \mathrm{t}\right) \mathrm{da} \mathrm{a}^{\prime} \mathrm{dr}^{\prime}=1\end{array}$ \\
\hline $\begin{array}{l}\text { I } \\
\text { Proportionate } \\
\text { age mixing }\end{array}$ & 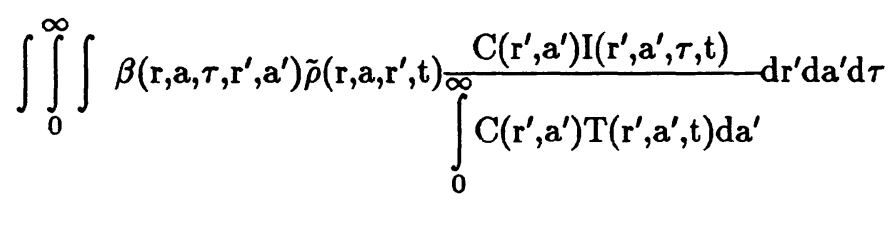 & $\begin{array}{c}\int_{0}^{\infty} \int_{0}^{\infty} \frac{\tilde{\rho}\left(\mathrm{r}, \mathrm{a}, \mathrm{r}^{\prime}, \mathrm{t}\right) \mathrm{C}\left(\mathrm{r}^{\prime}, \mathrm{a}^{\prime}\right) \mathrm{T}\left(\mathrm{r}^{\prime}, \mathrm{a}^{\prime}, \mathrm{t}\right)}{\int_{0}^{\infty} \mathrm{C}\left(\mathrm{r}^{\prime}, \mathrm{a}^{\prime}\right) \mathrm{T}\left(\mathrm{r}^{\prime}, \mathrm{a}^{\prime}, \mathrm{t}\right) \mathrm{da^{ \prime }}} \mathrm{dr}^{\prime} \\
=1\end{array}$ \\
\hline $\begin{array}{l}\text { II } \\
\text { Proportionate } \\
\text { activity mixing }\end{array}$ & $\iint_{0}^{\infty} \int \beta\left(\mathrm{r}, \mathrm{a}, \tau, \mathrm{r}^{\prime}, \mathrm{a}^{\prime}\right) \tilde{\rho}\left(\mathrm{r}, \mathrm{a}, \mathrm{a}^{\prime}, \mathrm{t}\right) \frac{\mathrm{C}\left(\mathrm{r}^{\prime}, \mathrm{a}^{\prime}\right) \mathrm{I}\left(\mathbf{r}^{\prime}, \mathrm{a}^{\prime}, \tau, \mathrm{t}\right)}{\int_{0}^{\infty} \mathrm{C}\left(\mathbf{r}^{\prime} \mathbf{a}^{\prime}\right) \mathrm{T}\left(\mathbf{r}^{\prime}, \mathbf{a}^{\prime}, \mathrm{t}\right) \mathrm{d} \mathbf{r}^{\prime}} \mathrm{dr} \mathbf{r}^{\prime} \mathrm{da} \mathbf{d} \tau$ & 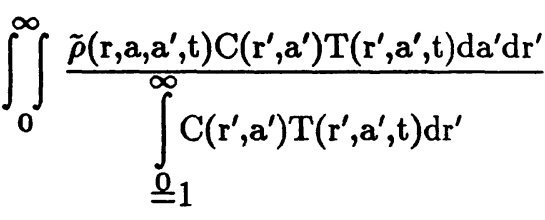 \\
\hline $\begin{array}{l}\mathrm{III}=\mathrm{I}+\mathrm{II} \\
\text { Proportionate } \\
\text { mixing }\end{array}$ & $\frac{1}{\int_{0}^{\infty} \int_{0} \mathrm{C}\left(\mathbf{r}^{\prime}, \mathrm{a}^{\prime}\right) \mathrm{T}\left(\mathbf{r}^{\prime}, \mathrm{a}^{\prime}, \mathrm{t}\right) \mathrm{da} \mathrm{a}^{\prime} \mathrm{dr}^{\prime}} \iint_{0}^{\infty} \int \beta\left(\mathrm{r}, \mathrm{a}, \tau, \mathrm{r}^{\prime}, \mathrm{a}^{\prime}\right) \mathrm{C}\left(\mathrm{r}^{\prime}, \mathrm{a}^{\prime}\right) \cdot$ & $\tilde{\rho}(\mathrm{r}, \mathrm{a}, \mathrm{t})=1$ \\
\hline $\begin{array}{l}\quad \text { IV } \\
\text { Uniform age } \\
\text { selectivity }\end{array}$ & $\iint_{0}^{\infty} \int \beta\left(\mathrm{r}, \mathrm{a}, \tau, \mathrm{r}^{\prime}, \mathrm{a}^{\prime}\right) \rho\left(\mathrm{r}, \mathrm{r}^{\prime}, \mathrm{a}^{\prime}, \mathrm{t}\right) \frac{\mathrm{I}\left(\mathrm{r}^{\prime}, \mathrm{a}^{\prime}, \tau, \mathrm{t}\right)}{\mathrm{T}\left(\mathbf{r}^{\prime}, \mathrm{a}^{\prime}, \mathrm{t}\right)} \mathrm{dr} \mathrm{r}^{\prime} \mathrm{da} \mathrm{a}^{\prime} \mathrm{d} \tau$ & $\rho\left(\mathrm{r}, \mathrm{r}^{\prime}, \mathrm{a}^{\prime}, \mathrm{t}\right) \mathrm{dr}^{\prime} \mathrm{da}^{\prime}=1$ \\
\hline $\begin{array}{l}\mathrm{V} \\
\text { Uniform activity } \\
\text { selectivity }\end{array}$ & $\iint_{0}^{\infty} \int \beta\left(\mathbf{r}, \mathbf{a}, \tau, \mathbf{r}^{\prime}, \mathbf{a}^{\prime}\right) \rho\left(\mathbf{a}, \mathbf{r}^{\prime}, \mathbf{a}^{\prime}, \mathrm{t}\right) \frac{\mathrm{I}\left(\mathbf{r}^{\prime}, \mathbf{a}^{\prime}, \tau, \mathrm{t}\right)}{\mathrm{T}\left(\mathbf{r}^{\prime}, \mathbf{a}^{\prime}, \mathrm{t}\right)} \mathrm{dr} \mathbf{r}^{\prime} \mathrm{d} \mathbf{a}^{\prime} \mathrm{d} \tau$ & $\int_{0} \rho\left(\mathrm{a}, \mathbf{r}^{\prime}, \mathrm{a}^{\prime}, \mathrm{t}\right) \mathrm{dr}^{\prime} \mathrm{da}^{\prime}=1$ \\
\hline $\begin{array}{l}\mathrm{VI}=\mathrm{IV}+\mathrm{V} \\
\text { Uniform age } \\
\text { of activity } \\
\text { selectivity }\end{array}$ & $\iint_{0}^{\infty} \int \beta\left(\mathrm{r}, \mathrm{a}, \tau, \mathrm{r}^{\prime}, \mathrm{a}^{\prime}\right) \rho\left(\mathrm{r}^{\prime}, \mathrm{a}^{\prime}, \mathrm{t}\right) \frac{\mathrm{I}\left(\mathrm{r}^{\prime}, \mathrm{a}^{\prime}, \tau, \mathrm{t}\right)}{\mathrm{T}\left(\mathrm{r}^{\prime}, \mathrm{a}^{\prime}, \mathrm{t}\right)} \mathrm{dr} \mathbf{r}^{\prime} \mathrm{da} \mathrm{a}^{\prime} \mathrm{d} \tau$ & $\int_{0}^{\infty} \int_{0} \rho\left(\mathrm{r}^{\prime}, \mathrm{a}^{\prime}, \mathrm{t}\right) \mathrm{dr}^{\prime} \mathrm{da}^{\prime}=1$ \\
\hline $\mathrm{I}+\mathrm{V}$ & Take $\tilde{\rho}\left(\mathrm{r}, \mathbf{a}, \mathbf{r}^{\prime}, \mathrm{t}\right)=\tilde{\rho}\left(\mathbf{a}, \mathbf{r}^{\prime}, \mathrm{t}\right)$ in $(\mathrm{I})$. No r dependence. & $\begin{array}{l}\text { These two conditions } \\
\text { place severe restrictions }\end{array}$ \\
\hline $\mathrm{II}+\mathrm{IV}$ & Take $\tilde{\rho}\left(\mathrm{r}, \mathrm{a}, \mathrm{a}^{\prime}, \mathrm{t}\right)=\tilde{\rho}\left(\mathrm{r}, \mathrm{a}^{\prime}, \mathrm{t}\right)$ in (II). No a dependence. & $\tilde{\rho}$ \\
\hline
\end{tabular}


Table Ib

\begin{tabular}{|c|c|}
\hline $\begin{array}{l}\text { Type \& } \\
\text { Name }\end{array}$ & $\begin{array}{c}\text { Pair Symmetry Condition } \\
\text { (iii) } \rho\left(\mathrm{r}, \mathrm{a}, \mathbf{r}^{\prime}, \mathrm{a}^{\prime}, \mathrm{t}\right) \mathrm{C}(\mathrm{r}, \mathrm{a}) \mathrm{T}(\mathrm{r}, \mathrm{a}, \mathrm{t})=\rho\left(\mathrm{r}^{\prime}, \mathrm{a}^{\prime}, \mathbf{r}, \mathrm{a}, \mathrm{t}\right) \mathrm{C}\left(\mathrm{r}^{\prime}, \mathrm{a}^{\prime}\right) \mathrm{T}\left(\mathrm{r}^{\prime}, \mathrm{a}^{\prime}, \mathrm{t}\right)\end{array}$ \\
\hline $\begin{array}{l}\text { I } \\
\text { Proportionate } \\
\text { age mixing }\end{array}$ & $\frac{\tilde{\rho}\left(\mathrm{r}, \mathrm{a}, \mathbf{r}^{\prime}, \mathrm{t}\right)}{\int_{0}^{\infty} \mathrm{C}\left(\mathbf{r}^{\prime}, \mathrm{a}^{\prime}\right) \mathrm{T}\left(\mathbf{r}^{\prime}, \mathrm{a}^{\prime}, \mathrm{t}\right) \mathrm{da^{ \prime }}}=\frac{\tilde{\rho}\left(\mathrm{r}^{\prime}, \mathrm{a}^{\prime}, \mathrm{r}, \mathrm{t}\right)}{\int_{0}^{\infty} \mathrm{C}(\mathrm{r}, \mathrm{a}) \mathrm{T}(\mathrm{r}, \mathrm{a}, \mathrm{t}) \mathrm{da}}$ \\
\hline $\begin{array}{c}\text { II } \\
\text { Proportionate } \\
\text { activity mixing }\end{array}$ & $\frac{\tilde{\rho}\left(\mathrm{r}, \mathrm{a}, \mathrm{a}^{\prime}, \mathrm{t}\right)}{\int_{0}^{\infty} \mathrm{C}\left(\mathbf{r}^{\prime}, \mathrm{a}^{\prime}\right) \mathrm{T}\left(\mathbf{r}^{\prime}, \mathrm{a}^{\prime}, \mathrm{t}\right) \mathrm{d} \mathbf{r}^{\prime}}=\frac{\tilde{\rho}\left(\mathbf{r}^{\prime}, \mathrm{a}^{\prime}, \mathrm{a}, \mathrm{t}\right)}{\int_{0}^{\infty} \mathrm{C}(\mathrm{r}, \mathrm{a}) \mathrm{T}(\mathrm{r}, \mathrm{a}, \mathrm{t}) \mathrm{dr}}$ \\
\hline $\begin{array}{l}\mathrm{III}=\mathrm{I}+\mathrm{II} \\
\text { Proportionate } \\
\text { mixing }\end{array}$ & $C(r, a) T(r, a, t)=C\left(r^{\prime}, a^{\prime}\right) T\left(r^{\prime}, a^{\prime}, t\right)$ \\
\hline $\begin{array}{l}\quad \text { IV } \\
\text { Uniform age } \\
\text { selectivity }\end{array}$ & $\rho\left(\mathrm{r}, \mathbf{r}^{\prime}, \mathrm{a}^{\prime}\right) \mathrm{C}(\mathrm{r}, \mathrm{a}) \mathrm{T}(\mathrm{r}, \mathrm{a}, \mathrm{t})=\rho\left(\mathbf{r}^{\prime}, \mathrm{r}, \mathrm{a}\right) \mathrm{C}\left(\mathrm{r}^{\prime}, \mathrm{a}^{\prime}\right) \mathrm{T}\left(\mathbf{r}^{\prime}, \mathrm{a}^{\prime}, \mathrm{t}\right)$ \\
\hline $\begin{array}{l}\mathrm{V} \\
\text { Uniform activity } \\
\text { selectivity }\end{array}$ & $\rho\left(\mathrm{a}, \mathrm{r}^{\prime}, \mathrm{a}^{\prime}\right) \mathrm{C}(\mathrm{r}, \mathrm{a}) \mathrm{T}(\mathrm{r}, \mathrm{a}, \mathrm{t})=\rho\left(\mathrm{a}^{\prime}, \mathrm{r}, \mathrm{a}\right) \mathrm{C}\left(\mathrm{r}^{\prime}, \mathrm{a}^{\prime}\right) \mathrm{T}\left(\mathrm{r}^{\prime}, \mathrm{a}^{\prime}, \mathrm{t}\right)$ \\
\hline $\begin{array}{l}\text { VI }=I V+V \\
\text { Uniform age } \\
\text { of activity } \\
\text { selectivity }\end{array}$ & $\tilde{\rho}\left(\mathrm{r}^{\prime}, \mathrm{a}^{\prime}\right) \mathrm{C}(\mathrm{r}, \mathrm{a}) \mathrm{T}(\mathrm{r}, \mathrm{a}, \mathrm{t})=\tilde{\rho}(\mathrm{r}, \mathrm{a}) \mathrm{C}\left(\mathrm{r}^{\prime}, \mathrm{a}^{\prime}\right) \mathrm{T}\left(\mathrm{r}^{\prime}, \mathrm{a}^{\prime}, \mathrm{t}\right)$ \\
\hline$I+V$ & These two conditions place severe restrictions on the \\
\hline $\mathrm{II}+\mathrm{IV}$ & \\
\hline
\end{tabular}




\section{REFERENCES}

Anderson, R.M. and R.M. May. (1987). Transmission dynamics of HIV infection. Nature 326, 137142.

Anderson, R.M. (1988). "The role of mathematical models in the study of HIV transmission and the epidemiology of AIDS.” Journal of AIDS. 1:241-256.

Anderson, R.M. (1989). Editorial Review: Mathematical and Statistical Studies of the epidemiology of HIV. AIDS. 3:333-346.

Anderson, R. M., S. P. Blythe, S. Gupta, and E. Konings. (1989). The transmission dynamics of the Human Immunodeficiency Virus Type 1 in the male homosexual community in the United Kingdom: the influence of changes in sexual behavior. (Manuscript.)

Blythe, S.P. and C. Castillo-Chavez. (1989). Like-with-like preference and sexual mixing models. Math. Biosci. 96, 221-238.

Busenberg, S. and C. Castillo-Chavez. (1989). Interaction, pair formation and force of infection terms in sexually transmitted diseases. In (C. Castillo-Chavez, ed.) Mathematical and Statistical Approaches to AIDS Epidemiology. Lecture Notes in Biomathematics 83, Springer-Verlag, Berlin, Heidelberg, New York, London, Paris, Tokyo, Hong Kong: 289-300.

Busenberg, S., K. Cooke, and H. Thieme. (1989). Demographic change and persistence of AIDS in a heterogeneous population. In print, SIAM J. Appl. Math.

Castillo-Chavez, C. (1989a). Some applications of structured models in population dynamics. In (S. A. Levin, T. G. Hallam, and L. J. Gross, eds.) Applied Mathematical Ecology, Biomathematics 18, Springer-Verlag, Berlin, Heidelberg, New York, London, Paris, Tokyo, Hong Kong: 450-470.

Castillo-Chavez, C. (ed.). (1989b). Mathematical and Statistical Approaches to AIDS Epidemiology. Lecture Notes in Biomathematics 83, Springer-Verlag, Berlin, Heidelberg, New York, London, Paris, Tokyo, Hong Kong. 
Castillo-Chavez, C. and S.P. Blythe. (1989). Mixing framework for social/sexual behavior. In (C. Castillo-Chavez, ed.) Mathematical and Statistical Approaches to AIDS Epidemiology. Lecture Notes in Biomathematics 83, Springer-Verlag, Berlin, Heidelberg, New York, London, Paris, Tokyo, Hong Kong: 275-288.

Castillo-Chavez, C. and S. Busenberg. (1989). Pair formation in age- and risk-structured populations. (Manuscript in preparation.)

Castillo-Chavez, C., H.W. Hethcote, V. Andreasen, S.A. Levin, and W.M. Liu. (1989a). Epidemiological models with age structure, proportionate mixing, and cross-immunity. J. Math. Biol. 27, 233-258.

Castillo-Chavez, C., K. Cooke, W. Huang, and S.A. Levin. (1989b). On the role of long periods of infectiousness in the dynamics of acquired immunodeficiency syndrome (AIDS). In (C. CastilloChavez, S.A. Levin, and C. Shoemaker, eds.) Mathematical Approaches to Problems in Resource Management and Epidemiology. Lecture Notes in Biomathematics 81, Springer-Verlag, Berlin, Heidelberg, New York, London, Paris, Tokyo, Hong Kong: 177-189.

Castillo-Chavez, C., K. Cooke, W. Huang, and S.A. Levin. (1989c). On the role of long incubation periods in the dynamics of acquired immunodeficiency syndrome (AIDS), Part 1. Single population models. J. Math. Biol. 27, 373-398.

Castillo-Chavez, C., K. Cooke, W. Huang, and S.A. Levin. (1989d). Results on the dynamics for models for the sexual transmission of the human immunodeficiency virus. Applied Mathematics Letter. 2(4):327-331.

Castillo-Chavez, C., K. Cooke, W. Huang, and S.A. Levin. (1989e). On the role of long incubation periods in the dynamics of acquired immunodeficiency syndrome (AIDS), Part 2. Multiple group models. In (C. Castillo-Chavez, ed.) Mathematical and Statistical Approaches to AIDS Epidemiology. Lecture Notes in Biomathematics 83, Springer-Verlag, Berlin, Heidelberg, New York, London, Paris, Tokyo, Hong Kong: 200-217. 
Castillo-Chavez, C., H.W. Hethcote, V. Andreasen, S.A. Levin, and W.M. Liu. (1988). Crossimmunity in the dynamics of homogeneous and heterogeneous populations. In (L. Gross, T.G. Hallam, and S.A. Levin, eds.) Mathematical Ecology. Proceedings, Autumn Course Research Seminars, Trieste 1986. World Scientific Publishing Co., Singapore: 303-316.

Cooke, K. L., D. A. Allers, and C. Castillo-Chavez. (1990). Mixing patterns and multiple endemic states in models of AIDS. (Manuscript).

Diekmann, O., J.A.P. Heesterbeek, and J.A.J. Metz. (1989). On the definition of $R_{0}$ in models for infectious diseases in heterogeneous populations. (Manuscript.)

Dietz, K. (1988). On the transmission dynamics of HIV. Math. Biosci. 90, 397-414.

Dietz, K. and K.P. Hadeler. (1988). Epidemiological models for sexually transmitted diseases. J. Math. Biol. 26, 1-25.

Francis, D.F., P.M. Feorino, J.R. Broderson, H.M. McClure, J.P. Getchell, C.R. McGrath, B. Swenson, J.S. McDougal, E.L. Palmer, A.K. Harrison, F. Barré-Sinoussi, J.C. Chermann, L. Montagnier, J.W. Curran, C.D. Cabradilla, and V.S. Kalyanaraman. (1984). Infection of chimpanzees with lymphadenopathy-associated virus. Lancet $2,1276-1277$.

Frederickson, A.G. (1971). A mathematical theory of age structure in sexual populations: Random mating and monogamous marriage models. Math. Biosci. 20, 117-143.

Gel'fand, I. M. and G. E. Shilov. (1964). Generalized Functions. Academic Press, New York, London. Volume 1.

Gupta, S., R. M. Anderson, and R. M. May. (1989). Networks of sexual contacts: implications for the pattern of spread of HIV. (Manuscript.)

Hadeler, K.P. (1989a). Pair formation in age-structured populations. Acta Applicandae Mathematicae $14,91-102$.

Hadeler, K.P. (1989b). Modeling AIDS in structured populations. (Manuscript.)

Hethcote, H.W. and Yorke, J.A. (1984). Gonorrhea Transmission Dynamics and Control, Lecture Notes in Biomathematics, No. 56, Springer-Verlag, Berlin Heidelberg New York Tokyo. 
Huang, W. (1989). Studies in differential equations and applications. Ph. D. Thesis, The Claremont Graduate School (December 1989), Claremont CA.

Huang, W., K. Cooke, and C. Castillo-Chavez. (1990). Stability and bifurcation for a multiple group model for the dynamics of HIV/AIDS transmission. (Manuscript.)

Hyman, J.M. and E.A. Stanley. (1988). A risk-based model for the spread of the AIDS virus. Math. Biosci. 90, 415-473.

Hyman, J.M. and Stanley, E.A. (1989). The effect of social mixing patterns on the spread of AIDS. In (C. Castillo-Chavez, S.A. Levin, and C. Shoemaker, eds.) Mathematical Approaches to Problems in Resource Management and Epidemiology. Lecture Notes in Biomathematics 81, Springer-Verlag, Berlin, Heidelberg, New York, London, Paris, Tokyo, Hong Kong: 190-199.

Jacquez, J.A., C.P. Simon, J. Koopman, L. Sattenspiel, and T. Perry. (1988). Modelling and analyzing HIV transmission: the effect of contact patterns. Math. Biosci. 92, 119-199.

Kendall, D.G. (1949). Stochastic processes and population growth. Roy. Statist. Soc., Ser. B 2, 230264.

Lange, J.M.A., D.A. Paul, H.G. Huisman, F. De Wolf, H. Van den Berg, C.A. Roel, S.A. Danner, J. Van der Noordaa, and J. Goudsmit. (1986). Persistent HIV antigenaemia and decline of HIV core antibodies associated with transition to AIDS. Brit. Med. J. 293, 1459-1462.

May, R.M. and R.M. Anderson. (1989). The transmission dynamics of human immunodeficiency virus (HIV). Phil. Trans. R. Soc. London B 321, 565-607.

Nold, A. (1980). Heterogeneity in disease-transmission modeling. Math. Biosci. 52, 227-240.

Salahuddin, S.Z., J.E. Groopman, P.D. Markham, M.G. Sarngaharan, R.R. Redfield, M.F. McLane, M. Essex, A. Sliski, and R.C. Gallo. (1984). HTLV-III in symptom-free seronegative persons. Lancet 2, 1418-1420.

Schwager, S. J., C. Castillo-Chavez, and H. Hethcote. (1989). Statistical and mathematical approaches in HIV/AIDS modeling: a review. In (C. Castillo-Chavez, ed.) Mathematical and Statistical Approaches to AIDS Epidemiology. Lecture Notes in Biomathematics 83, SpringerVerlag, Berlin, Heidelberg, New York, London, Paris, Tokyo, Hong Kong: 2-37. 
Sattenspiel, L. and C.P. Simon. (1988). The spread and persistence of infectious diseases in structured populations. Math. Biosci. 90, 341-366.

Sattenspiel, L. (1987a). Population structure and the spread of disease. Human Biology 59, 411-438.

Sattenspiel, L. (1987b). Epidemics in nonrandomly mixing populations: a simulation. American Journal of Physical Anthropology, 73, 251-265.

Schwartz, L. (1966). Théorie des distributions. Hermann, Paris.

Thieme, H.R. and C. Castillo-Chavez. (1989a). On the role of variable infectivity in the dynamics of the human immunodeficiency virus. In (C. Castillo-Chavez, ed.) Mathematical and Statistical Approaches to AIDS Epidemiology. Lecture Notes in Biomathematics 83, Springer-Verlag, Berlin, Heidelberg, New York, London, Paris, Tokyo, Hong Kong: 157-177.

Thieme, H.R. and C. Castillo-Chavez. (1989b). On the possible effects of infection-age-dependent infectivity in the dynamics of HIV/AIDS. (Manuscript.)

Waldstätter, R. (1989). Pair formation in sexually transmitted diseases. In (C. Castillo-Chavez, ed.) Mathematical and Statistical Approaches to AIDS Epidemiology. Lecture Notes in Biomathematics 83, Springer-Verlag, Berlin, Heidelberg, New York, London, Paris, Tokyo, Hong Kong: $260-274$. 